NASA Technical Memorandum 87323

\title{
Plume Characteristics of Single-Stream and Dual-Flow Conventional and Inverted-Profile Nozzles at Equal Thrust
}

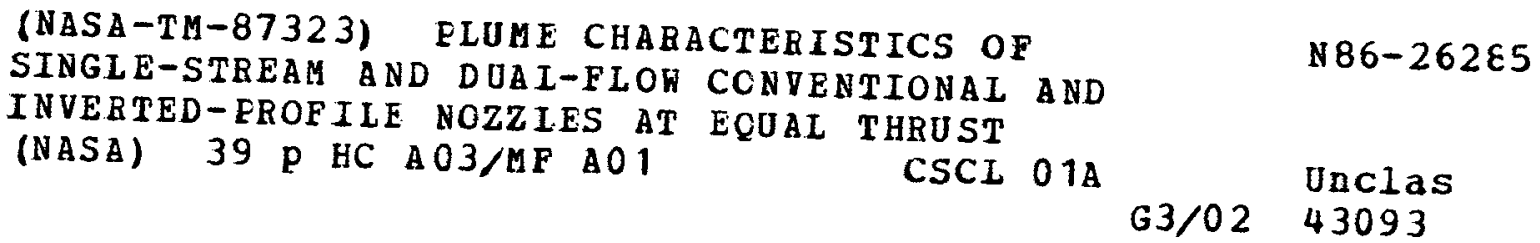

Uwe H. von Glahn and Jack H. Goodykoontz

Lewis Research Center

Cleveland, Ohio

Prepared for the

Fourth Applied Aerodynamics Conference sponsored by the American Institute of Aeronautics and Astronautics San Diego, California, June 9-11, 1986 


\title{
PLUME CHARACTERISTICS OF SINGLE-STREAM AND DUAL-FLOW
}

\section{CONVENTIONAL AND INVERTED-PROFILE NOZZLES AT EQUAL THRUST}

\author{
Uwe H. von Glahn and Jack H. Goodykoontz \\ National Aeronautics and Space Administration \\ Lewis Research Center \\ Cleveland, ohio 44135
}

\section{SUMMARY}

The plume velocity and temperature decay rates of single-stream, conventional dual-flow and inverted-profile dual-flow nozzles are compared at equal values of ideal thrust over a wide range of flow conditions. The comparisons are made in terms of constant velocity and temperature contour maps. The results show that both dual-flow nozzle types have much greater plume velocity and temperature decay rates than those of equivalent thrust singlestream nozzles when the respective secondary flows were at ambient temperature. With hot secondary flows, the inverted-profile dual-flow plumes decayed significantly faster than those of single-stream nozzles; however, the decay rates for the conventional dual-flow streams were about the same as those for the single-stream nozzles. Consequently, with hot secondary flows, the invertedprofile dual-flow plumes decayed much faster than the conventional dual-flow plumes at equal thrust.

\section{INTRODUCTION}

As part of a growing research activity in the control of aerodynamic flows, the modification of jet exhaust plume characteristics by nozzle design in order to obtain rapid velocity and temperature decay rates has received increased consideration. Included among such nozzle designs are those associated with: (a) commercial supersonic alrcraft for which the jet exhaust noise must be reduced to acceptable community noise levels, and (b) STOL aircraft for which the exhaust plume velocity and temperature levels must be reduced before the jet impinges on the deflected flap system during STOL operation in order to provide flap loads and temperatures within acceptable structural limits and minimum weights. An example of the latter type aircraft is the McDonnell Douglas $\mathrm{C}-17$.

The turbofan nozzle systems included herein consist of: (a) conventional dual-flow nozzles in which the inner (primary) stream is at both a higher temperature and velocity than that of the outer fan or secondary stream and (b) inverted-profile nozzles in which the outer (primary) stream is at both a higher temperature and velocity than that of the inner (secondary) stream (refs. 1 to 3). In inverted-prof 11 e nozzle systemis, the normal turbofan core and fan flows can be cross-ducted within the engine nacelle, as shown schematically in figure 1. Alternatively, an ejector can be used to introduce a cold inner flow with the hot engine flow cross-ducted to provide a hot outer flow (ref. 4). Both of these methods provide a relatively thin hot annular exhaust - flow that decays rapidly with axial distance downstream of the nozzle exit plane. 
In this paper, high subsonic jet velocity and temperature plumes for single-stream nozzles are compared in terms of contour maps with those for conventional and inverted-profile dual-stream nozzles. The comparisons are made on the basis of equal total ideal thrust calculations. Data obtained with two dual-flow nozzles of nominal area ratio, AR, of 1.9 and 3.2 are used in the present study.

Conventional dual-flow nozzle area ratios, $A R$, of 1.9 and 3.2 represent nozzles used with current high bypass turbofan engines. These engines generally have exhaust velocity ratios, $U_{0} / U_{j}$, from 0.7 to 0.85 , with a heated inner (core) flow and $t_{0} / t_{j}$ values in the range of 0.2 to 0.4 .

Inverted-profile dual-flow nozzles area ratios, AR, of 1.9 and 3.2 represent nozzles that would be used with low bypass turbofan engines: The engines could have small to large exhaust velocities depending on whether the secondary air (inner stream) is provided by an engine fan or an ejector. For most installations, $t_{0} / t_{i}$ values in the range of 2 to 5 would be appropriate.

The inner nozzles for the two-stream nozzles were circular in cross section. The inner nozzle alone was used to obtain the single-stream nozzle data. Each stream of the dual-flow nozzles could be independently controlled for the appropriate exhaust temperature and/or flow. Consequently, data were obtained over a wide range of flow and temperature levels. Initially plume contour maps for the dual-stream nozzles are compared with those of a single stream nozzle of equal ideal thrust. Then, comparisons between various combinations of the conventional and inverted profile dual-flow nozzle contour maps are made, again at equal ideal thrust.

\section{NOMENCLATURE}
A nozzle area
AR nozzle area ratio, $A_{0} / A_{i}$
D nozzle diameter
M Mach number
p pressure
$R$ nozzle radius measured from nozzle centerline
$T$ thrust
$t$ static temperature
u velocity
$x$ axial distance measured from nozzle exit.plane 


\author{
Subscripts \\ a ambient \\ c conventional dual-flow \\ $i \quad$ inner \\ ip inverted-profile dual-flow \\ J fet (single stream) \\ o outer
}

APPARATUS AND PROCEDURE

Facility

A photograph of the dual-flow heated-jet facility used to obtain the data base for the present work is shown in figure 2. Unheated laboratory air was used to supply flow for two parallel flow lines; one line for the inner nozzle and the other for the outer nozzle. Each flow line had its own air and fuel flow control and measuring systems. The air was heated by a jet engine combustor installed in each line. The system was designed to give maximum nozzle exhaust temperatures of about $1100 \mathrm{~K}$ and nozzle pressure ratios up to 3.0 in each of the flow lines.

\title{
Nozzles
}

The dual-flow nozzles used for the present work are the same as the NASA nozzles used in references 4 and 5 . Pertinent dimensions of these nozzles are given in figure 3 . The inner nozzle was common to both configurations and the coaxial nozzle area ratio was changed by changing the outer nozzle. The outer wall of the inner nozzle was coated with a high temperature ceramic material to minimize heat transfer between the two streams. The interior of the upstream portion of the inner nozzle supply was also lined with insulating material. For the single-stream data, only the inner nozzle was used.

\section{Instrumentation}

Mean flow characteristics were measured using pressure probes and thermocouples mounted in such a manner as to facilitate axial and radial measurement of the jet plume. The measured total and static pressures and the total temperature profiles were used to generate radial profiles of mean velocity, total and static temperature, and Mach number at each axial measurement station.

In addition, to those measurements, instrumentation was provided to measure air flow rates and nozzle pressure and temperature levels. Further detalls are given in reference 5 . 
Procedure

Nozzle pressures and temperatures were varied over a range of conditions so that the test matrix included a wide range of jet velocity and temperature ratios. A summary of the nozzle configurations and flow conditions included herein are given in table $I$. In all cases, steady state conditions were attained for each flow condition before pressures and temperatures were recorded. Where necessary upstream total temperatures were corrected for radiation losses and used with the average upsream pressures to calculate an ideal exhaust velocity. Static temperatures were derived from the total temperature and Mach number. Further details of corrections made to the measured data are detailed in references 4 and 5 .

\section{TYPICAL DATA AND ANALYSIS}

Typical measured radial profiles of velocity and temperature for singlestream and both conventional and inverted-profile dual-flow nozzles are shown in figures 4 to 6 , respectively. From such data, the velocity and temperature plumes were developed and plotted in terms of contour maps of constant velocity and temperature for each nozzle area ratio and flow condition. Representative contour maps are shown in figure 7 for the single-stream nozzle. The data

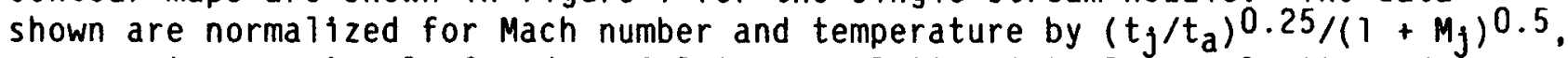
a parameter previously found useful in correlating jet plume velocity and temperature decay data (refs. 4 to 6 ).

Representative velocity and temperature contour maps for conventional and inverted-profile dual-flow nozzles are shown in figure 8 . The contour maps are based on local velocity and temperature reported in references 4 and 5 .

The ideal thrust for each flow condition was calculated for all three nozzles using conventional methods based on nozzle area and stream conditions. For the dual-flow nozzles, the thrust level of each stream was calculated separately and then summed.

\section{FLOW FIELO SCALING PROCEDURE}

In order to compare the flow fields of single-stream nozzle plumes with those of dual-flow nozzles, the single-stream constant velocity and temperature contour lines were extrapolated from normalized plume decay and calculated thrust data to the characteristic flow conditions and calculated total thrust levels of the dual-flow nozzles.

Normalized constant velocity and temperature contour lines for the singlestream nozzle plumes used herein are shown in figure 9 and include a range of velocity and temperature contour line ratios from 0.5 to 0.95 . Although constant contour line values of 0.3 and 0.4 were shown in figure 8 , the analysis herein is restricted to values of 0.5 or greater because the measured data for the lower values were generally too imprecise and erratic.

The constant contour maps shown in figure 9 were used to obtain values of radial distance, $R$, and axial distance, $X$, for a single-stream nozzle operating at the characteristic flow conditions of a dual-flow nozzle. For conventional dual-flow nozzles, the characteristic flow conditions are based on $M_{j}$ and $t_{j}$ which are used in place of $M_{j}$ and $t_{j}$, respectively in 
figure 9. Similarly, for inverted-profile dual-flow nozzles, the characteristic flow conditions are based on $M_{0}$ and $t_{0}$.

In order to obtain plume contour maps at equal thrust, the calculated single-stream nozzle thrust, normalized to the dual flow nozzle flow conditions, was scaled to the calculated thrust of the dual-flow nozzle. An equivalent single-stream diameter-to-actual. single-stream diameter ratio for equal thrust was:calculated as follows:

(a) Conventional dual-flow nozzle:

(b) Inverted-profile nozzle:

$$
\frac{D_{c}}{D_{j}}=\frac{U_{j}}{U_{i}}\left[\left(\frac{T_{c}}{T_{j}}\right)\left(\frac{t_{i}}{t_{j}}\right)\left(\frac{p_{j}}{p_{i}}\right)\right]^{0.5}
$$

$$
\frac{D_{i p}}{D_{j}}=\frac{U_{j}}{U_{0}}\left[\left(\frac{T_{i p}}{T_{j}}\right)\left(\frac{t_{0}}{\bar{t}_{j}}\right)\left(\frac{p_{j}}{p_{0}}\right)\right]^{0.5}
$$

The $R$ and $X$ values obtained previously fromi figure 9 are now each mulitiplied by the appropriate equivalent diameter ratio (eq. 1 or 2). By connecting the appropriate points, the resulting curves constitute equal thrust single-stream plume constant contour maps that can be compared with the appropriate dual-flow plume contour maps based on the measured data. Equations (1) and (2) apply to both plume velocity and temperature contour maps.

\section{RESULTS}

In the following sections, comparisons are made at equal ideal thrust between the exhaust plumes obtained for the nozzle configurations used in the study. The comparisons include:

(1) Conventional dual-flow with single-stream nozzle plumes.

(2) Inverted-profile dual-flow with single-stream nozzle plumes

(3) Effect of nozzle area ratio for the same nozzle type on nozzle plumes.

(4) Comparison of conventional with inverted-profile dual-flow plumes.

Each comparison includes consideration of both velocity and temperature plume characteristics. The (a) portions of the figures show the velocity comparisons and the (b) portions show the temperature comparisons.

\section{Conventional Dual-Flow Nozzles}

In figures 10 to 14 are shown the constant contour maps for conventional dual-flow nozzle plumes typical of turbofan-type engine installations in which both streams exhaust at a common exit plane. Also shown for comparison in these figures are the constant contour maps for single-stream nozzle plumes representing turbojet engine installations at equal ideal thrust.

Velocity. - For all cases shown in figures 10 to 14 , the axial extents of the comparable constant velocity contour maps are less for the conventional 
dual-flow nozzles than those for the single flow nozzle at equal thrust. With a constant outer stream temperature, an increase in the nominal velocity ratio, $U_{0} / U_{1}$, from 0.68 to 0.77 (figs. $10(a)$ and $11(a)$ ), respectively caused the 0.90 and 0.95 contour lines of the conventional dual-flow plume to approach the axial extent of the single-stream plume without significantly affecting the rest of the constant contour lines.

With an ambient temperature outer stream, the overall nozzle radius at the nozzle exit plane for the conventional dual-flow nozzles was always smaller than that for the equivalent single-stream nozzle (figs. 10(a) to 12(a)). However, with a heated outer stream of a nominal $545 \mathrm{~K}$ (figs. 13(a) and 14(a)), the overall nozzle radii for the two nozzle types was substantially the same.

From the preceding discussion, it is apparent that the flow conditions $U_{0} / U_{j}$ and $t_{0} / t_{j}$ are both important parameters in determining the velocity decay characteristics of conventional dual-flow nozzles relative to those of equivalent thrust single-stream nozzles.

\section{Inverted-Profile Dual-Flow Nozzles}

Constant contour maps for inverted-profile dual-flow nozzle plumes are shown in figures 15 to 21 . Such nozzles were studied as a part of efforts to reduce the jet noise levels of proposed commercial supersonic aircraft (refs. 1 to 3). Also included again in figures 15 to 21 are the constant contour maps for single-stream nozzle plumes at equal ideal thrust.

Velocity. - In figures $15(\mathrm{a})$ and $16(\mathrm{a})$, constant velocity contour maps of inverted-profile dual-flow plumes with ambient temperature inner streams amd nominal $U_{0} / U_{1}$ values of 1.5 are compared to those for single-stream at equal thrust values. The contour maps for the two nozzle types illustrate that the velocity decays much more rapidly with the inverted profile nozzles than that with a single-stream nozzle. In particular, the contour lines from 0.8 to 0.95 indicate decay rates for the inverted-profile dual-flow plumes of at least twice as great as those for the single-stream plumes. Note that for these flow conditions, the overall nozzle exit plane radii for the single-stream and inverted profile dual-flow nozzles are substantially the same.

In figures $17(a)$ and $18(a)$ are shown comparisons of the plume constant contour maps for both types of nozzles, with the inverted-profile dual-flow nozzle velocity ratio, $U_{0} / U_{j}$, raised to 3.4 and with ambient temperature. inner streams. For both the area ratio 1.9 and 3.2 invertedprofile dual-flow nozzles shown, the plume velocity decay rates are still twice as great as those for the single-stream nozzle for constant contour lines in the range of 0.9 and 0.95 for the 1.9 area ratio nozzle and 0.8 to 0.95 for the 3.2 area ratio nozzle. For lower constant contour line values, the comparable contour lines are nearly the same. At these lower contour line values, the inverted-profile velocity plumes have mixed out and follow axtal and radial decay rates similar to those associated with single-stream nozzle plumes. For both of the inverted-profile dual-flow nozzles shown in figures $17(\mathrm{a})$ and $18(\mathrm{a})$, the overall. nozzle exit plane radii are greater than those for the equivalent thrust single-stream nozzles. This was not the case when the velocity ratio was 1.5 (figs. 15(a) and 16(a)). 
In figures $19(a)$ and $20(a)$ are shown comparisons of the plume contour maps for inverted-proflle dual-flow nozzles having the inner stream heated to a nominal $530 \mathrm{~K}$ and the equivalent thrust single-stream nozzles. Both area ratio inverted-profile dual-flow nozzle plumes provide similar shapes, retaining the rapid decay characteristics noted in the previous figures. For these flow conditions, the overall nozzle exit plane radii are substantially the same for both single-stram and inverted-profile dual-flow nozzles.

Temperature. - With a nominal velocity ratio, $U_{0} / U_{j}$, of 1.5 and an ambient temperature inner stream, the plume temperature decays faster with the inverted-profile dual-flow nozzle plumes than that with equivalent thrust single-stream nozzles (figs. $15(b)$ and $16(b)$ ). The increased decay rate amounts to a factor of about three for comparable contour lines over the range of data included.

An increase in the velocity ratio from 1.5 to 3.4 (ambient temperature inner stream) reduces the difference in the plume temperature decay rates between the two nozzle types as shown in figures $17(b)$ and 18(b). At constant contour lines from 0.7 to 0.95 the temperature decay rate for both inverted. profile dual-flow plumes is greater that of the single-stream plume. However, for the 3.2 area ratio dual-flow nozzle, the temperature decay rate for the single-stream plume is greater than that for the inverted-profile plume for constant contour lines of 0.5 to 0.7 (fig. 18(b)). For the inverted-profile nozzle with an area ratio of 1.9 (fig. $17(\mathrm{~b}))$, the temperature decay rate for the inverted-profile nozzle with an area ratio of 1.9 (fig. $17(\mathrm{~b})$ ), the temperature decay rate for the inverted-profile plume is somewhat greater than that of the single-stream nozzle plume even at constant contour lines of 0.5 and 0.6 .

With the inner stream heated to a nominal $539 \mathrm{~K}$, the plume temperature decay rate was significantly greater for both inverted-profile dual-flow noz<les (AR, 1.9 and 3.2 ) compared with that for single-stream nozzles (figs. 19 (b) and 20(b)). In general, the inverted-profile nozzle plume decay rates were from two to three time greater than the comparable single-stream plume decay rates, with the higher decay rates occurring at constant contour line values of 0.8 to 0.95 .

A single set of temperature decay data was obtained with the $A R=3.2$ nozzle in which the outer stream was heated to $579 \mathrm{~K}$, the inner stream was at ambient temperature and the velocity ratio, $U_{0} / U_{1}$, was 1.0 . These data are shown in figure 21 together with the equivalent thrust single-stream nozzle temperature decay contour lines. The temperature decay rates with the heated outer stream are greatly increased over those for the single-stream nozzle temperature decay rates by a factor of up to four, depending on the specific constant contour line. The nozzle exit plane radil of both nozzles was approximately the same for the equal thrust constant contour lines shown in figure 21 .

\section{Dual-Flow Nozzle Area Ratio Effects}

In this section, the constant contour maps at equal thrust of the dualflow nozzles are compared at each dual-flow mode in order to evaluate the effect of nozzle area ratio on the plum decay. 


\section{Conventional Dual-Flow Nozzles}

Velocity. - A comparison of velocity constant contour maps at equal thrust is shown in figure 22(a) for conventional dual-flow plumes having nozzle area ratios, $A_{0} / A_{j}$, of 1.9 and 3.2 and similar flow conditions. The plume velocity decay characteristics are substantially the same for both nozzles, with the 3.2 area-ratio nozzle plume decay rate slightly less than that of the 1.9 area-ratio nozzle. The overall nozzle exit plane radii are substantialy the same for both nozzles. However, the inner nozzle radius of the smaller area ratio nozzle is somewhat larger, as would be expected, than that of the larger area ratio nozzle.

Temperature. - The temperature constant contour maps at equal thrust for the preceding two conventional dual-flow nozzle plumes are shown in figure 22(b). The temperature plumes show similar trends to those discussed for the velocity constant contour maps comparison.

\section{Inverted-Profile Dual-Flow Nozzles}

Velocity. - With the inner stream at ambient temperature, the plume velocity decay rates of the two invertedprofile dual-flow nozzles shown in figure $23(a)$ are quite similar with the larger area ratio (3.2) nozzle plume decay rate being slightly greater than that of the smaller area ratio (1.9) nozzle. However, the 1.9-area-ratio nozzle outer stream flow tends to be directed more toward the nozzle centerline than that of the 3.2-area-ratio nozzle.

With a heated inner stream, the plume velocity decay rate of the smailer area ratio (1.9) nozzle is much greater, by a factor of up to about twice, that of the larger area ratio (3.2) nozzle as shown in figure 24(a). The overall nozzle exit plane radif of both nozzles are about the same, but the inner nozzle radius of the 1.9 area-ratio nozzle is, as expected, larger than that of the 3.2 area-ratio nozzle. Both nozzle outer stream flows tend to be directed toward the nozzle centerline for the constant contour maps shown.

Temperature. - In genera1, the plume temperature decay rates provide the same trends as those discussed for the velocity decay constant contour maps (figs. 23(b) and 24(b)). Only in the case of a heated inner stream ( $f$ ig. $24(\mathrm{~b})$ ) was any significant difference in the decay rates noted between the small and large area ratio nozzles. For this operating condition, the plume temperature decay rates for the two nozzles, as evidenced by the constant contour maps, were substantially similar. Only for contour line values of 0.5 to 0.7 , was the temperature decay rate somewhat greater for the larger area ratio nozzle than that for the smaller area ratio nozzle.

\section{Comparison of Conventional and Inverted-..Profile Dual-Flow Nozzle Plumes}

In this section, the plume decay characteristics, in terms of constant contour maps, for conventional and inverted-profile dual-flow nozzles will be compared on the basis of equal thrust. This represents comparisons of high bypass engine configuration plumes (conventional dual-flow nozzle) with those of inverted-profile low bypass engine configuration plumes. 
Velocity. - The velocity constant contour maps for conventional and inverted profile dual-flow nozzle plumes are shown in figure 25(a) for nozzles with area ratios of 1.9 and 3.2 , respectively. For both nozzles, the respective secondary stream temperatures ( $t_{0}$ for the conventional dual-flow nozzle and $t_{i}$ for the inverted-profile nozzle) were ambient. In general, the plume velocity decay rate is greater for the inverted-profile plume than that of the conventional dual-flow plume for constant contour lines from 0.8 to 0.95 . However, for constant contour lines from 0.5 to 0.7 , the velocity decay rate is greater for the conventional dual-flow plume than that for the invertedprofile plume. Note that the overall nozzle exit plane radius of the conventional dual-flow nozzle is smaller by about 20 percent than that of the inverted-profile nozzle.

In figure 26(a) the velocity constant contour maps for a nozzle area ratio of 1.9 are shown for a conventional and an inverted-profile dual-flow nozzle with the secondary flows heated to a nominal $535 \mathrm{~K}$ temperature. For this flow condition, the velocity decay rate for the inverted-profile plume is significantly greater than that for the conventional dual-flow plume. except in the case of the 0.5 constant contour line. Also, in contrast to the previous case, the overall nozzle exit plane radil for both nozzles are now substantially the same.

In figure $27(\mathrm{a})$, the constant contour maps for a nozzle area ratio of 3.2 are shown for a conventional and an inverted-profile dual-flow nozzle. The secondary streams of both nozzles are heated to a nominal temperature of $535 \mathrm{~K}$. As was the case for the smaller 1.9-area-ratio nozzle, the velocity decay rate of the inverted-profile plume was much greater than that of the conventional dual-flow plume for all constant contour lines shown. For these conditions and nozzles, the overall nozzle exit plane radius of the invertedprofile dual-flow nozzle was slightly larger than that of the conventional dual-flow nozzle.

Temperature. - As. shown in Figure 25(b), with an ambient temperature secondary stream the temperature decay rate for the inverted-profile plume $(A R=3.2)$ was somewhat greater than that of the conventional dual-flow plume $(A R=1.9)$, particularly in the range of constant contour lines from 0.8 to 0.95 .

For the same nozzle $(A R=1.9)$ when the respective secondary stream was heated to a temperature of $535 \mathrm{~K}$, the inverted-prof fle plume temperature decay rates were much greater than those associated with the conventional dual-flow plume as shown in figure 26(b). Similar results were generally obtained for the larger $A R=3.2$ nozzle as shown in figure $27(b)$. Only for the constant contour line of 0.5 was the temperature decay rate greater, by a small amount, for the conventional dual-flow plume than that for the inverted-profile dualflow plume.

\section{CONCLUSIONS}

Comparisons at equal thrust of single-stream, conventional dual..flow and inverted-profile dual-flow nozzle plumes over a wide range of operating conditions provide the following conclusions.

1. With the secondary stream at ambient temperature, the plume velocity and temperature decay rates for both conventional and inverted-proflle dual-flow 
nozzles are significantly greater, by factors up to four, than those of equivalent thrust single-stream nozzles.

2. With a heated secondary stream $(535 \mathrm{~K})$, the plume velocity and temperature decay rates of conventional dual-flow nozzles were substantially the same as those of equivalent thrust single-stream nozzles. However, the plume velocity and temperature decay rates for the inverted-profile dual-flow nozzles with the secondary stream heated were substantially greater than those for the equivalent thrust single-stream nozzles.

3. Comparisons of the plume decay rates for dual-flow nozzles of the same type but different area ratios indicated generaliy no significant differences. An exception occurred in the case of the velocity decay of the inverted-profile dual-flow nozzle operating with a heated inner stream. Under this condition, the 1.9 area-ratio-nozzle velocity decay rate was somewhat greater than that of the 3.2 area-ratio nozzle at equal thrust.

4. Comparisons of the plume decay rates for the conventional and invertedprofile dual flow nozzles indicated no significant differences when the respective secondary streams were at ambient temperature. However, with heated secondary streams, both the inverted-profile plume velocity and temperature decay rates were greater than those of the conventional dual-flow nozzles operating at equal thrust.

5. The specific velocity and temperature plume decay requirements will determine, to a large degree, the selection of the dual-flow type of nozzle configuration for a particular aircraft-engine application.

\section{REFERENCES}

1. Knott, P.R.; Blozy, J.T.; and Staid, P.S., "Acoustic and Aerodynamic Performance Investigation of Inverted Velocity Profile Coannular Plug Nozzles," NASA CR-3149, 1981.

2. Larson, R.S.; Nelson, D.P.; and Stevens, B.S.; "Aerodynamic and Acoustic Investigation of Inverted Velocity Profile Coannular Exhaust Nozzle Models and Development of Aerodynamic and Acoustic Prediction Procedures," NASA CR-3168, 1979 .

3. Vdoviak, J.W.; Knott, P.R.; and Ebacker, J.J.; "Aerodynamic/Acoustic Performance of YJ 101/Double Bypass VCE With Coannular Plug Nozzle," General Electric Co., Cincinnati, OH R80-AEG369, Jan. 1981.

(NASA CR-159869)

4. von Glahn, U., Goodykoontz, J. and Wasserbauer, C., "Velocity and Decay Characteristics of Inverted-Profile Jets," AIAA Paper 86-0312, Jan. 1986.

5. von Glahn, U., Goodykoontz, J. and Wasserbauer, C., "Velocity and Temperature Characteristics of Two-Stream, Coplanar Jet Exhaust Plumes," AIAA Paper 84-2205, Aug. 1984.

6. von Giahn, U.H.; "On Some Flow Characteristics of Conventional and Excited Jets," AIAA Paper 84-0532, Jan. 1984. 
TABLE I. - SUMMARY OF NOZZZLE CONFIGURATIONS AND ASSOCIATED FLOW CONDITIONS

\begin{tabular}{|c|c|c|c|c|c|c|c|c|c|}
\hline Nozzle type & AR & $\begin{array}{l}U_{0}, \\
\mathrm{~m} / \mathrm{s}\end{array}$ & $\begin{array}{l}U_{i}, \\
\mathrm{~m} / \mathrm{s}\end{array}$ & $\begin{array}{c}t_{0}, \\
k\end{array}$ & $\begin{array}{c}t_{j}, \\
k\end{array}$ & $M_{0}$ & $M_{i}$ & $U_{0} / U_{i}$ & $t_{0} / t_{i}$ \\
\hline Single stream & $\begin{array}{l}\cdots \cdots \\
\cdots \cdots \\
\cdots-\end{array}$ & $\begin{array}{l}-\cdots \\
\cdots- \\
-- \\
--\end{array}$ & $\begin{array}{l}506 \\
338 \\
590 \\
274\end{array}$ & $\begin{array}{l}\cdots \cdots \\
\cdots \cdots \\
\cdots \cdots \\
\cdots-\end{array}$ & $\begin{array}{r}706 \\
1094 \\
964 \\
800\end{array}$ & $\begin{array}{l}\cdots \\
\cdots \cdots \\
\cdots \cdots \\
\cdots\end{array}$ & $\begin{array}{r}0.981 \\
.534 \\
.965 \\
.539\end{array}$ & $\begin{array}{l}\cdots \cdots \\
\cdots \cdots- \\
\cdots \cdots- \\
\cdots \cdots\end{array}$ & $\begin{array}{l}-\cdots- \\
\cdots-\cdots \\
\cdots-- \\
\cdots-\end{array}$ \\
\hline $\begin{array}{c}\text { Conventional } \\
\text { dual-flow }\end{array}$ & $\begin{array}{l}1.9 \\
1.9 \\
1.9 \\
3.2 \\
3.2\end{array}$ & $\begin{array}{l}280 \\
314 \\
314 \\
248 \\
308\end{array}$ & $\begin{array}{l}360 \\
459 \\
459 \\
287 \\
454\end{array}$ & $\begin{array}{l}237 \\
248 \\
547 \\
292 \\
542\end{array}$ & $\begin{array}{r}783 \\
1029 \\
1039 \\
822 \\
1056\end{array}$ & $\begin{array}{r}0.906 \\
.996 \\
.680 \\
.763 \\
.667\end{array}$ & $\begin{array}{l}.642 \\
.733 \\
.737 \\
.520 \\
.747\end{array}$ & $\begin{array}{r}0.77 \\
.68 \\
.68 \\
.86 \\
.67\end{array}$ & $\begin{array}{r}0.30 \\
.24 \\
.53 \\
.36 \\
.51\end{array}$ \\
\hline $\begin{array}{l}\text { Inverted-profile } \\
\text { dual-flow }\end{array}$ & $\begin{array}{l}1.9 \\
1.9 \\
3.2 \\
3.2 \\
3.2 \\
3.2 \\
3.2 \\
3.2\end{array}$ & $\begin{array}{l}459 \\
597 \\
297 \\
527 \\
593 \\
417 \\
458 \\
457\end{array}$ & $\begin{array}{l}309 \\
175 \\
291 \\
171 \\
172 \\
292 \\
305 \\
310\end{array}$ & $\begin{array}{r}1042 \\
981 \\
554 \\
1018 \\
968 \\
972 \\
1038 \\
1026\end{array}$ & $\begin{array}{l}532 \\
294 \\
255 \\
265 \\
274 \\
236 \\
233 \\
529\end{array}$ & $\begin{array}{l}.733 \\
.969 \\
.635 \\
.842 \\
.977 \\
.684 \\
.730 \\
.732\end{array}$ & $\begin{array}{l}.675 \\
.522 \\
.907 \\
.528 \\
.521 \\
.948 \\
.995 \\
.679\end{array}$ & $\begin{array}{l}1.49 \\
3.41 \\
1.02 \\
3.09 \\
3.49 \\
1.43 \\
1.50 \\
1.47\end{array}$ & $\begin{array}{l}1.96 \\
3.34 \\
2.17 \\
3.84 \\
3.53 \\
4.12 \\
4.45 \\
1.94\end{array}$ \\
\hline
\end{tabular}




\section{ORIGINAL PAGE IS \\ OF POOR QUALTY}

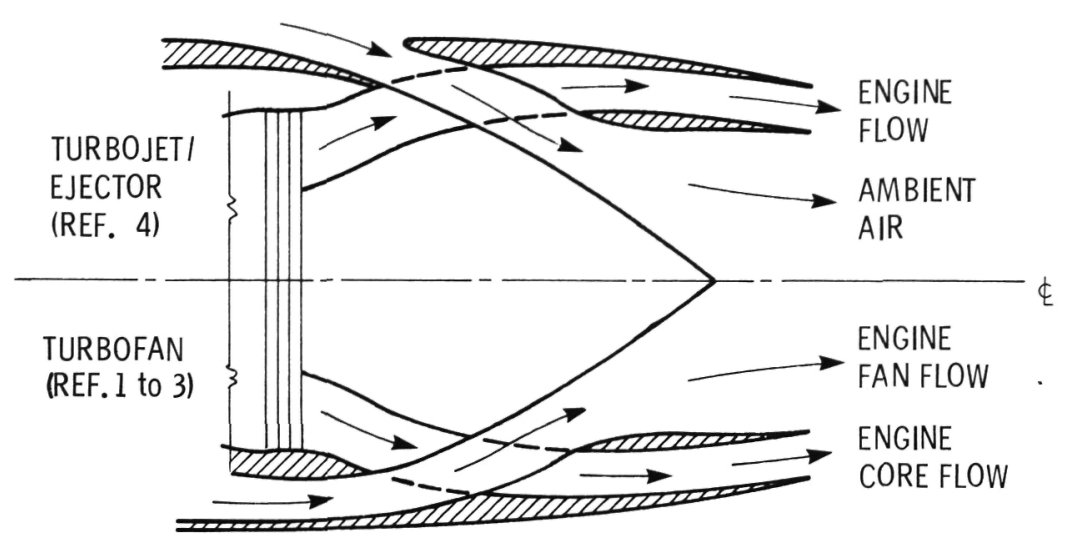

Figure 1. - Schematic of inverted-profile nozzle concepts。

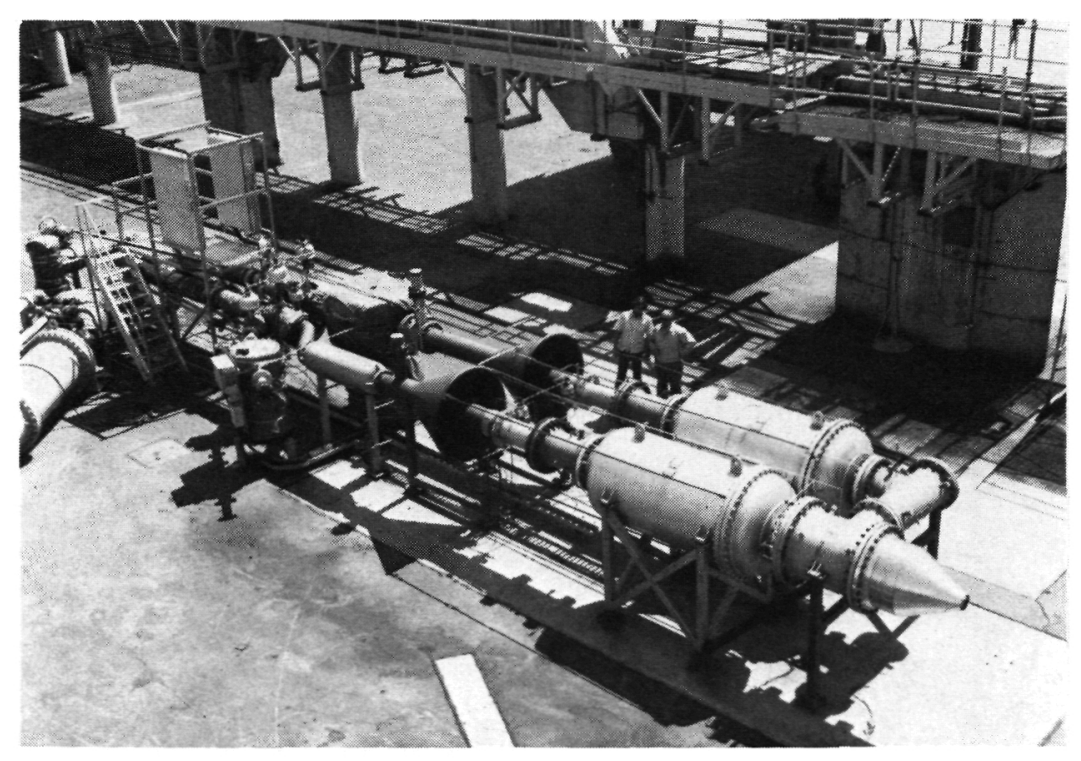

Figure 2. - NASA-Lewis dual-stream heated jet facility. 


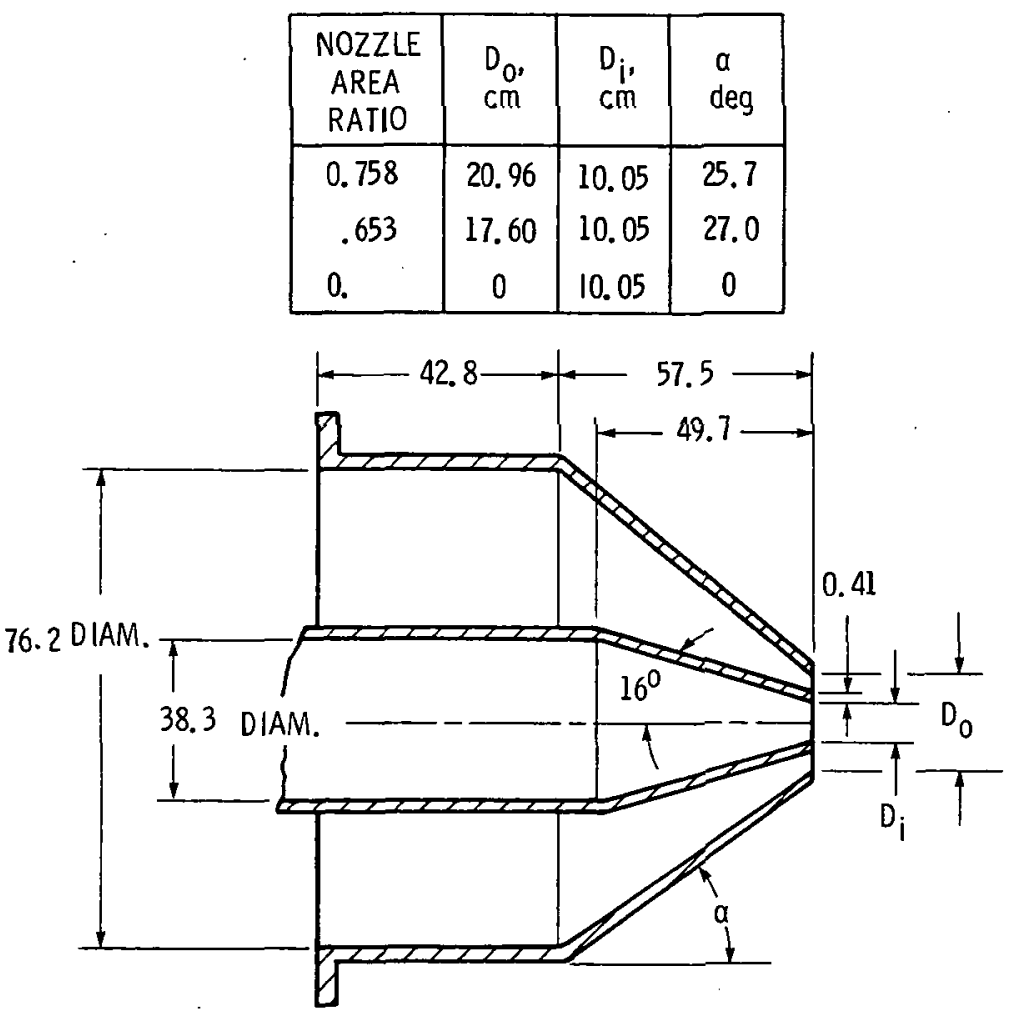

Figure 3. - Nozzle schematic, All dimensions in centimeters. 


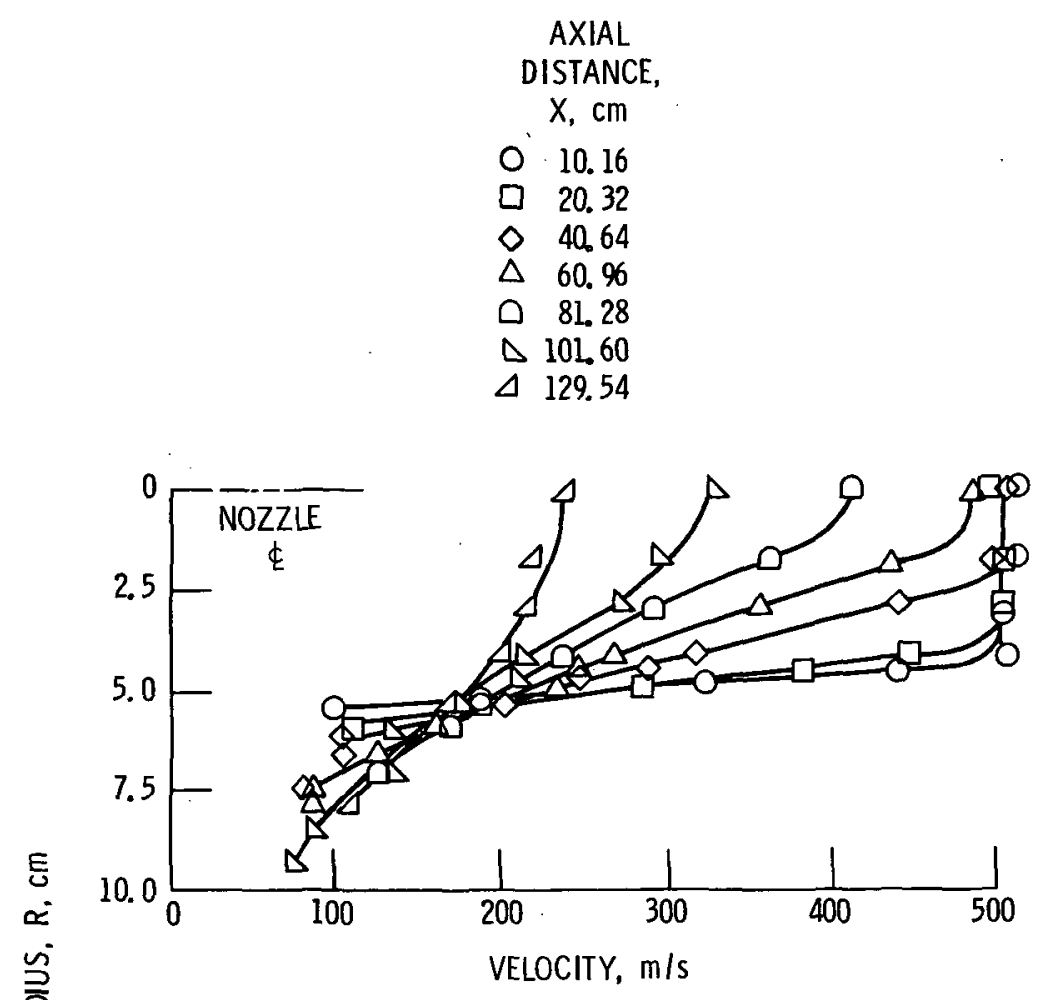

(a) Radial velocity profiles.

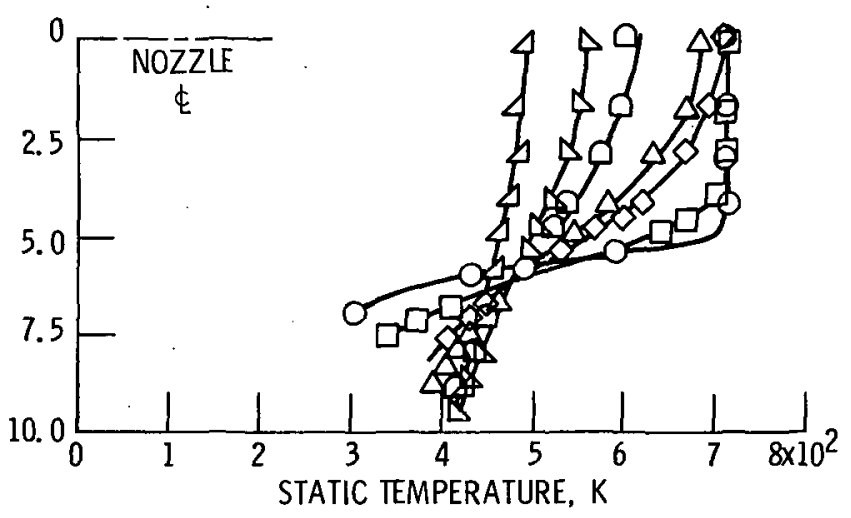

(b) Radial temperature profiles.

Figure 4. - Typical radial velocity/temperature profiles for a single-stream nozzle. $U_{j} ; 506 \mathrm{~m} / \mathrm{s} ; t_{j}, 706 \mathrm{~K}$. 


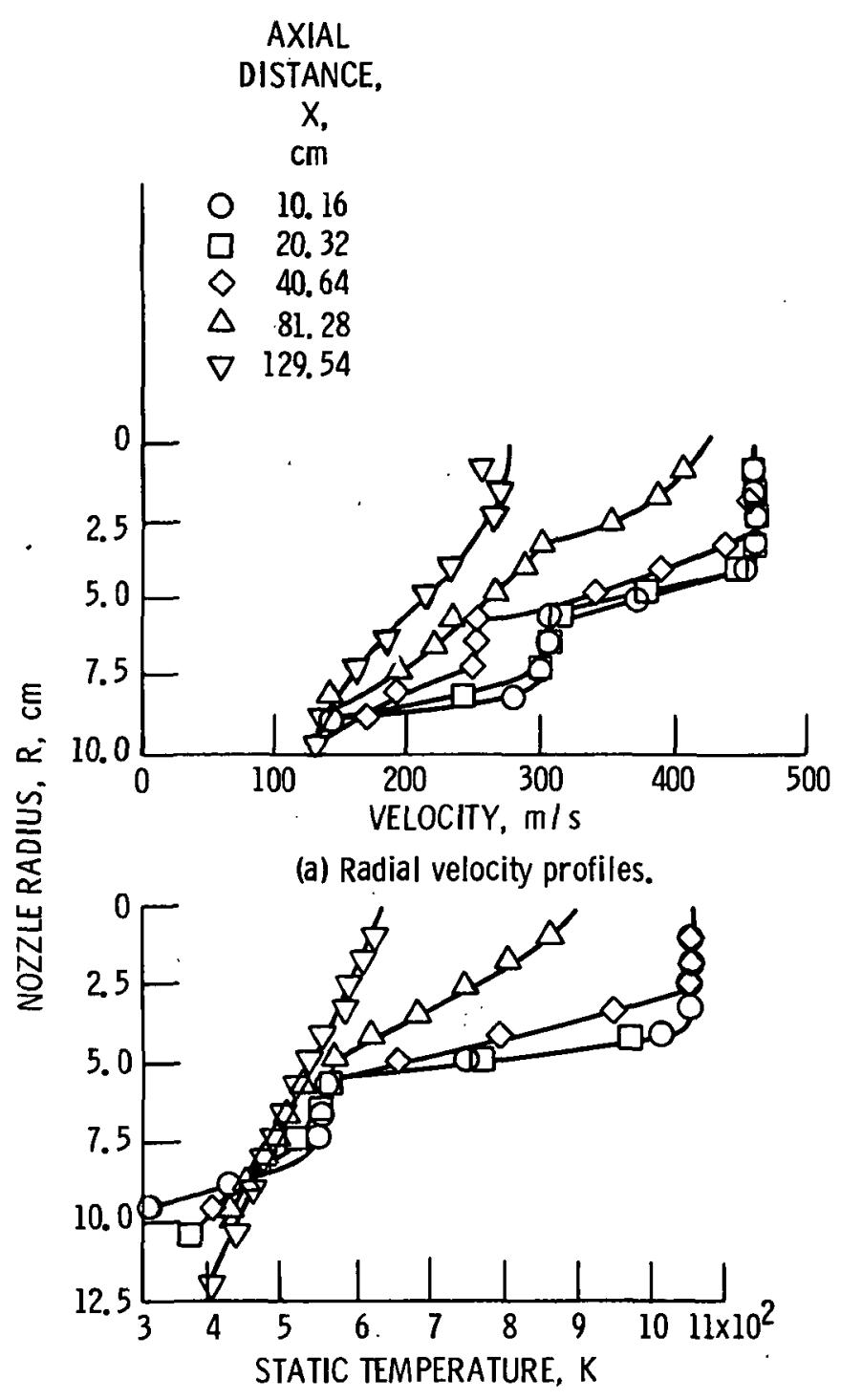

(b) Radial temperature profiles.

Figure 5. - Typical radial velocity and temperature profiles for conventional dualflow nozzle. AR, 3.2; $U_{0} / U_{j}, 0.67 ; U_{i j}$, $454 \mathrm{~m} / \mathrm{s} ; \mathrm{t}_{0} / \mathrm{t}_{\mathrm{i}}, 0.51 ; \mathrm{t}_{\mathrm{i}}, 1056 \mathrm{~K}$. 


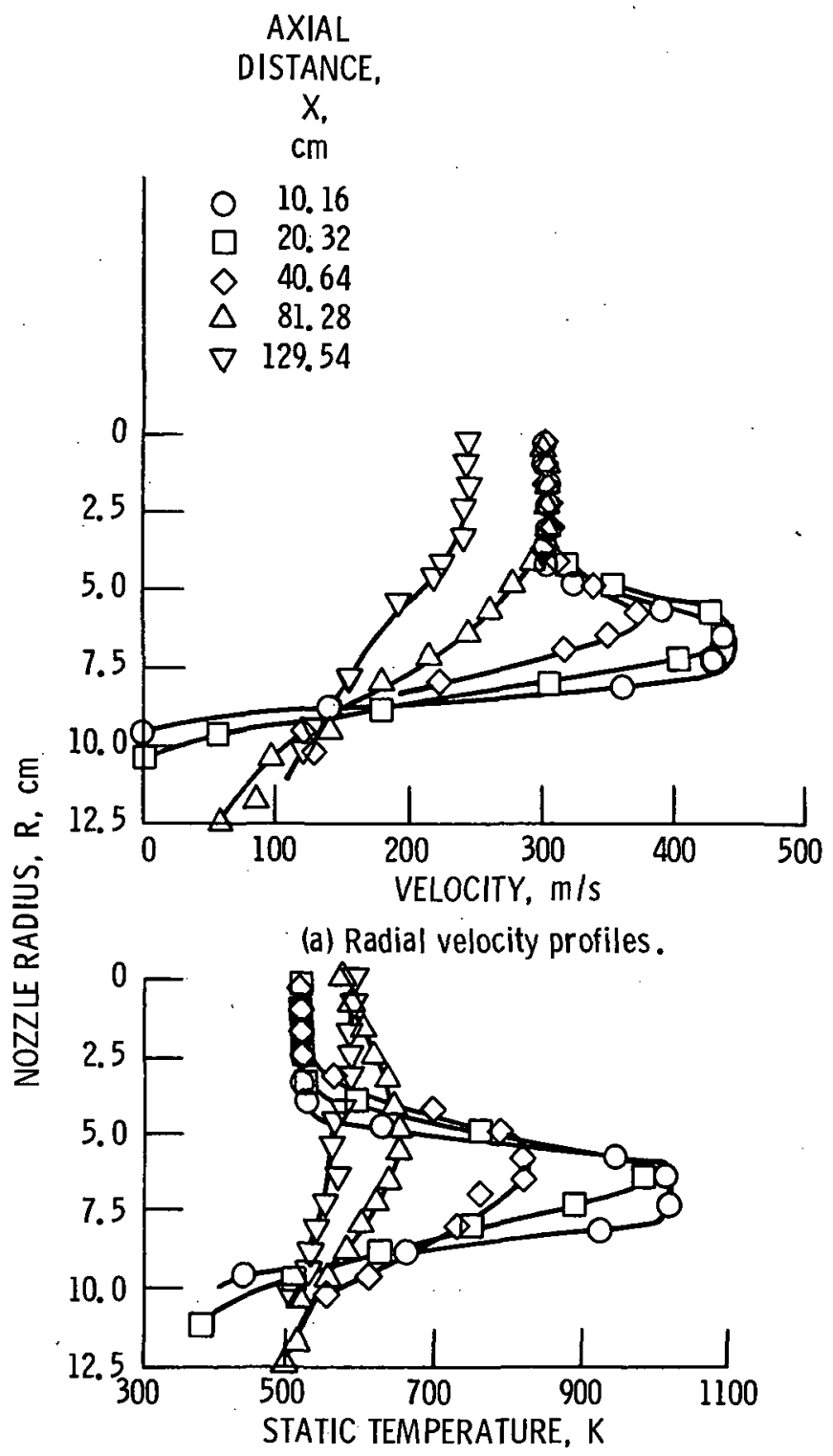

(b) Radial temperature profiles.

Figure 6. - Typical radial velocity and temperature profiles for inverted-profile dualflow nozzle. $A R, 1.9 ; U_{0} / U_{j}, 1.5 ; U_{0}$. $459 \mathrm{~m} / \mathrm{s} ; \mathrm{t}_{0} / \mathrm{t}_{\mathrm{i}}, 2.0 ; \mathrm{t}_{0}, 1042 \mathrm{~K}$. 


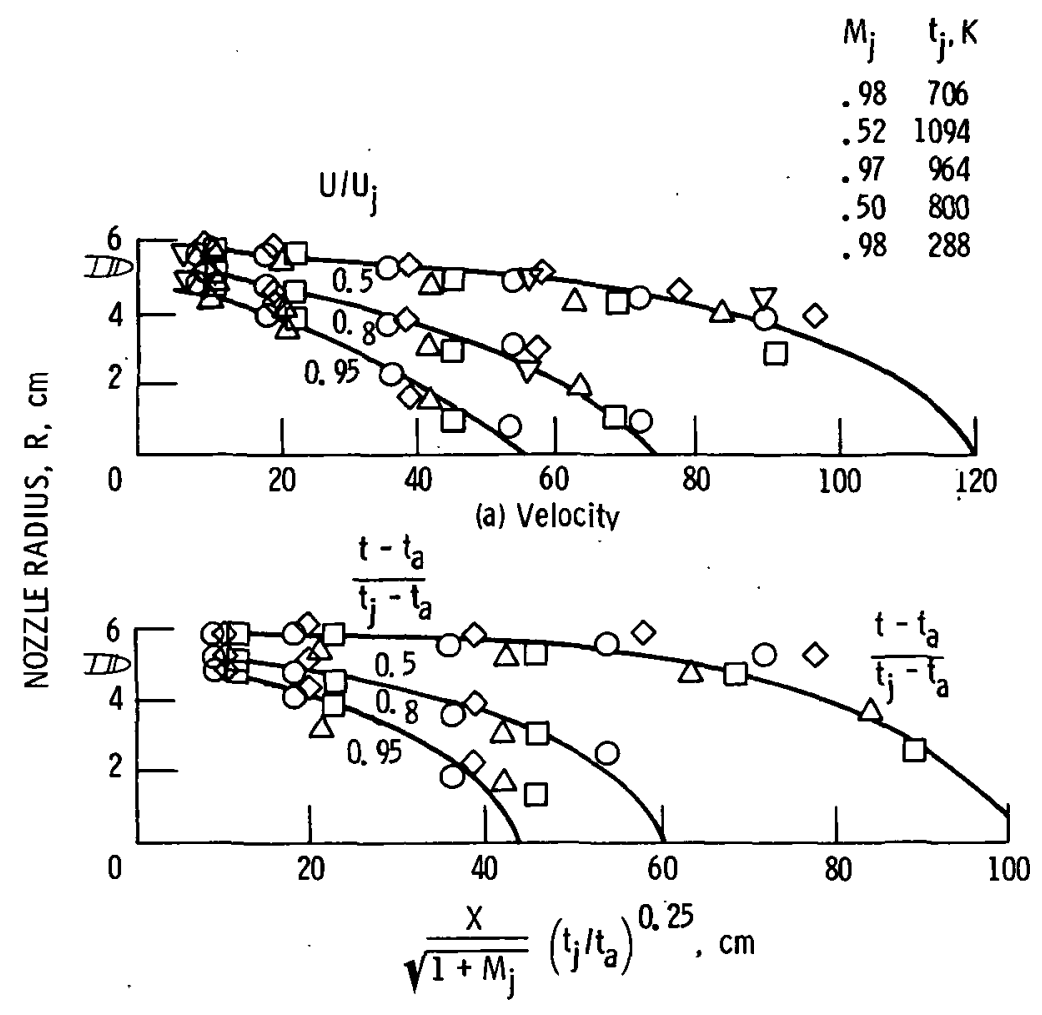

(b) Temperature.

Figure 7. - Representative single-stream nozzle plume contour maps. 


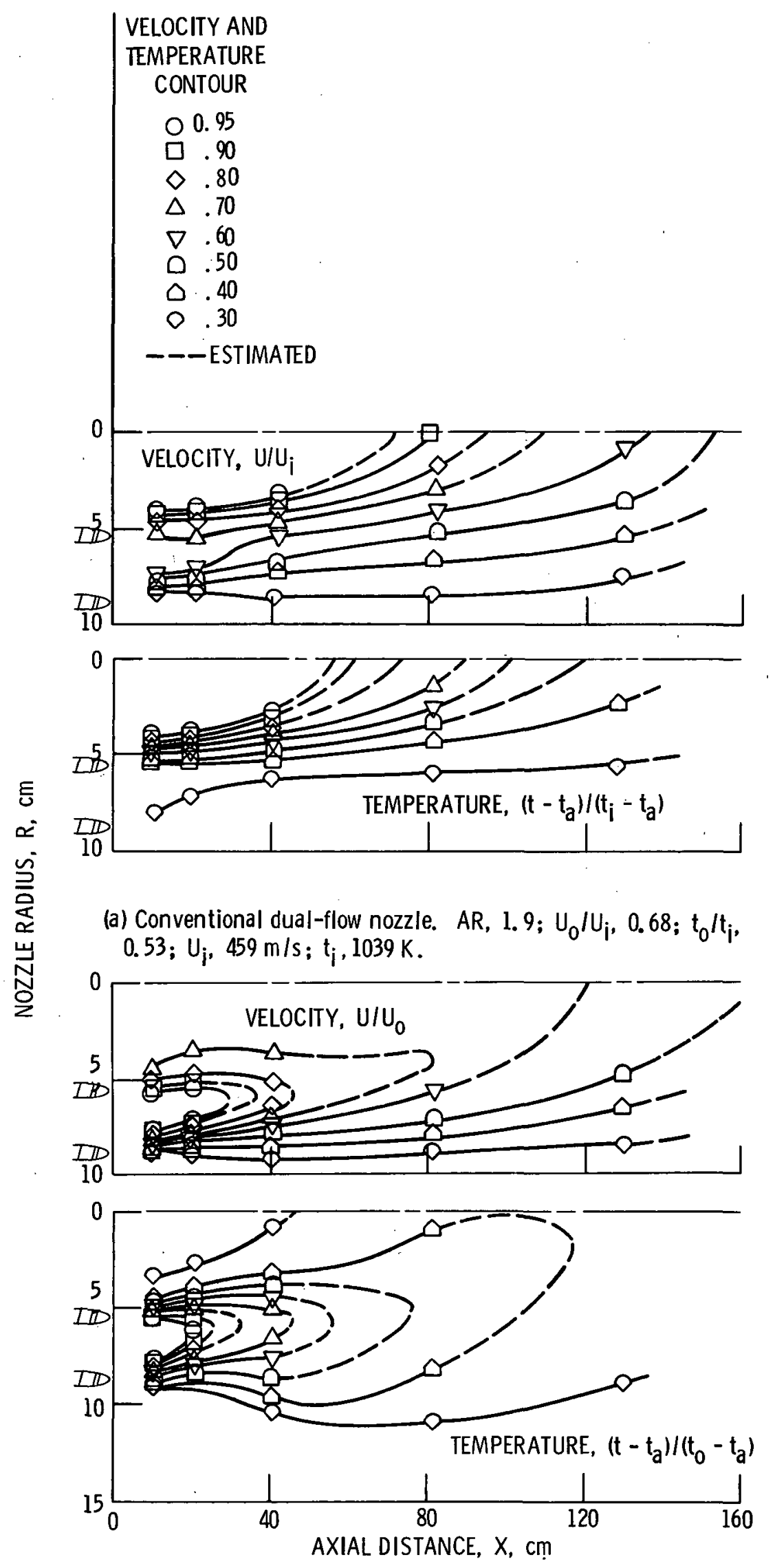

(b) Inverted-profile dual-flow nozzle. AR, $1.9 ; U_{0} / U_{i}, 1.49$; $t_{0} / t_{i}, 1.96 ; U_{0}, 459 \mathrm{~m} / \mathrm{s} ; t_{0}, 1042 \mathrm{~K}$.

Figure 8. - Representative dual-flow nozzle plume contour maps. 


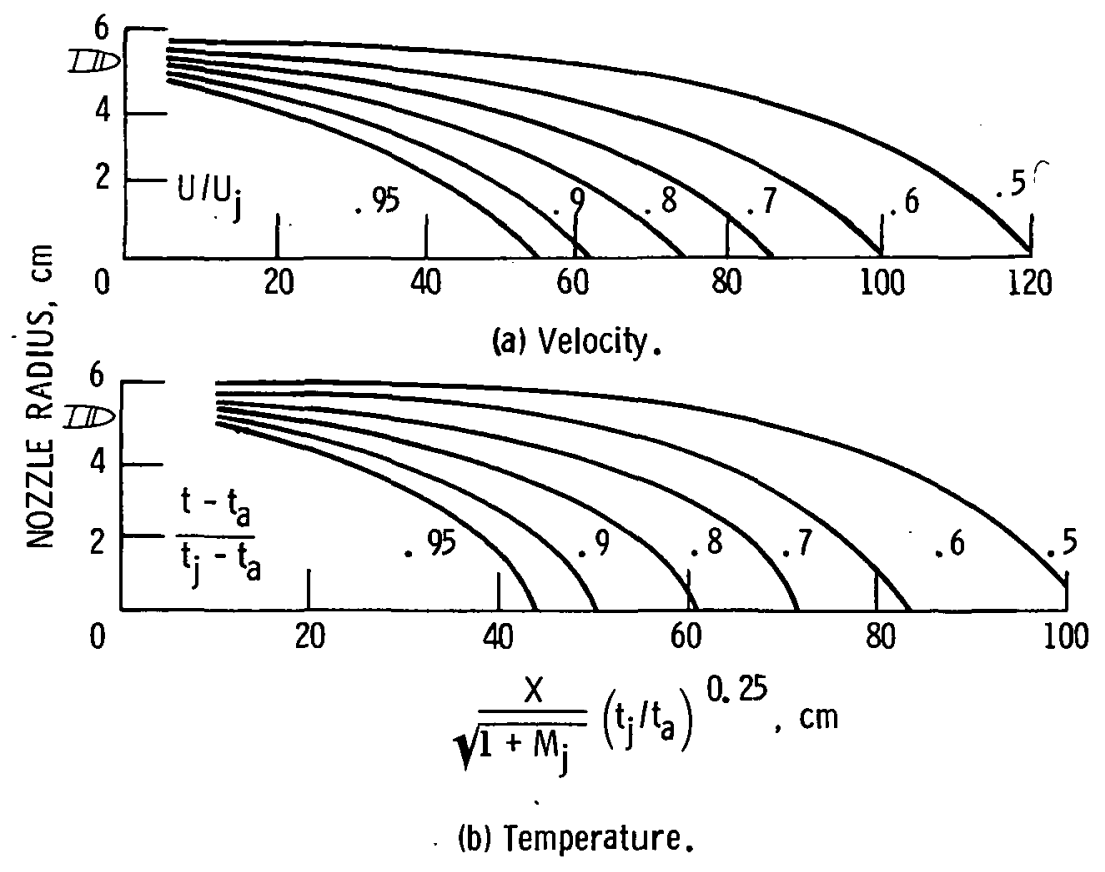

Figure 9. - Normalized single-stream nozzle plume contour maps. 

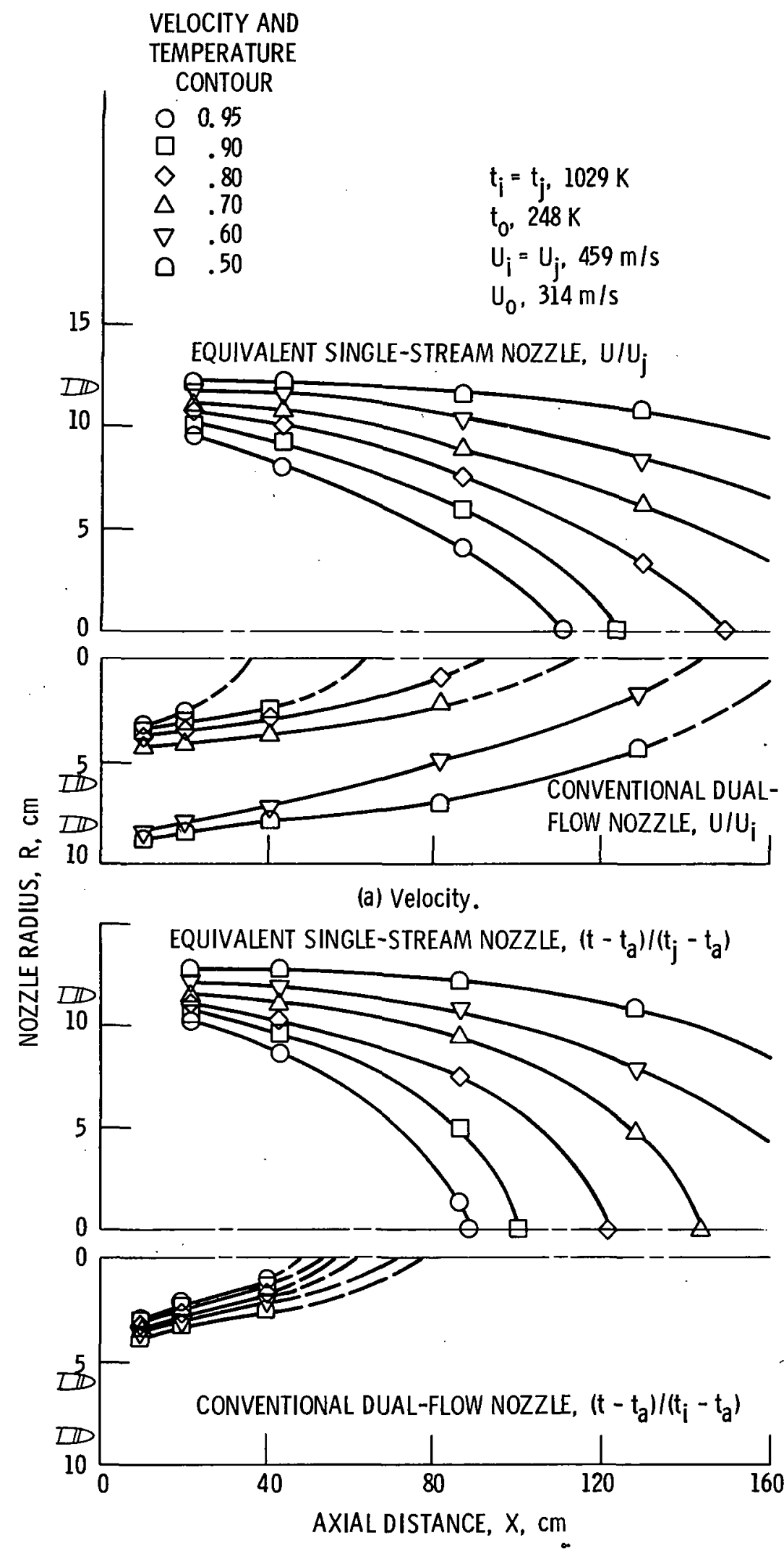

(b) Temperature.

Figure 10. - Velocity and temperature contour map comparison of cold outer-stream conventional dual-flow nozzle plumes with equivalent thrust single-stream nozzle plumes. AR, 1.9; $U_{0} / U_{j}, 0.68 ; t_{0} / t_{i}, 0.24$. 


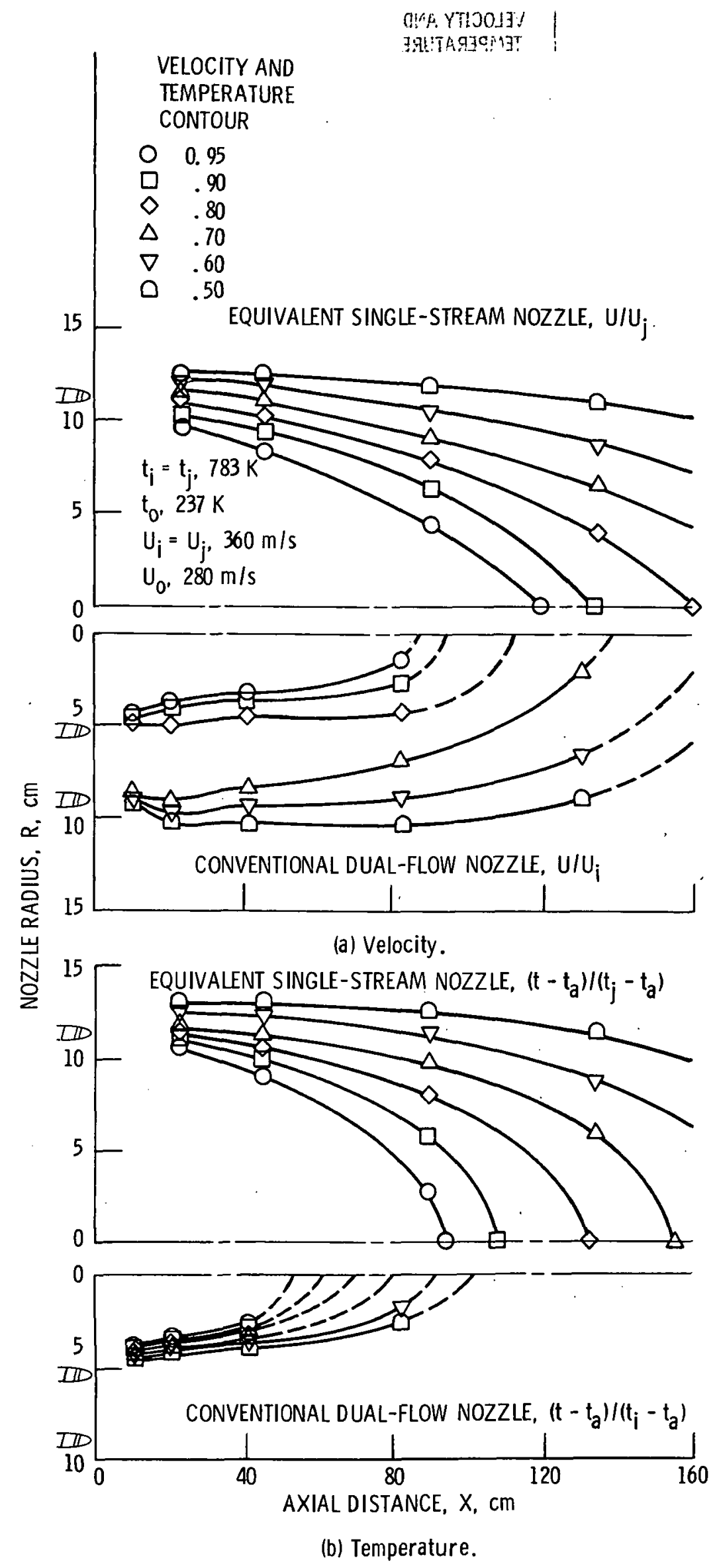

Figure 11. - Velocity and temiperature contour map comparison of cold outer-stream conventional dual-flow nozzle plumes with equivalent thrust single-stream nozzle plumes.

AR, $1: 9 ; U_{0} / U_{i}, 0.77 ; t_{0} / t_{i}, 0.30$. 


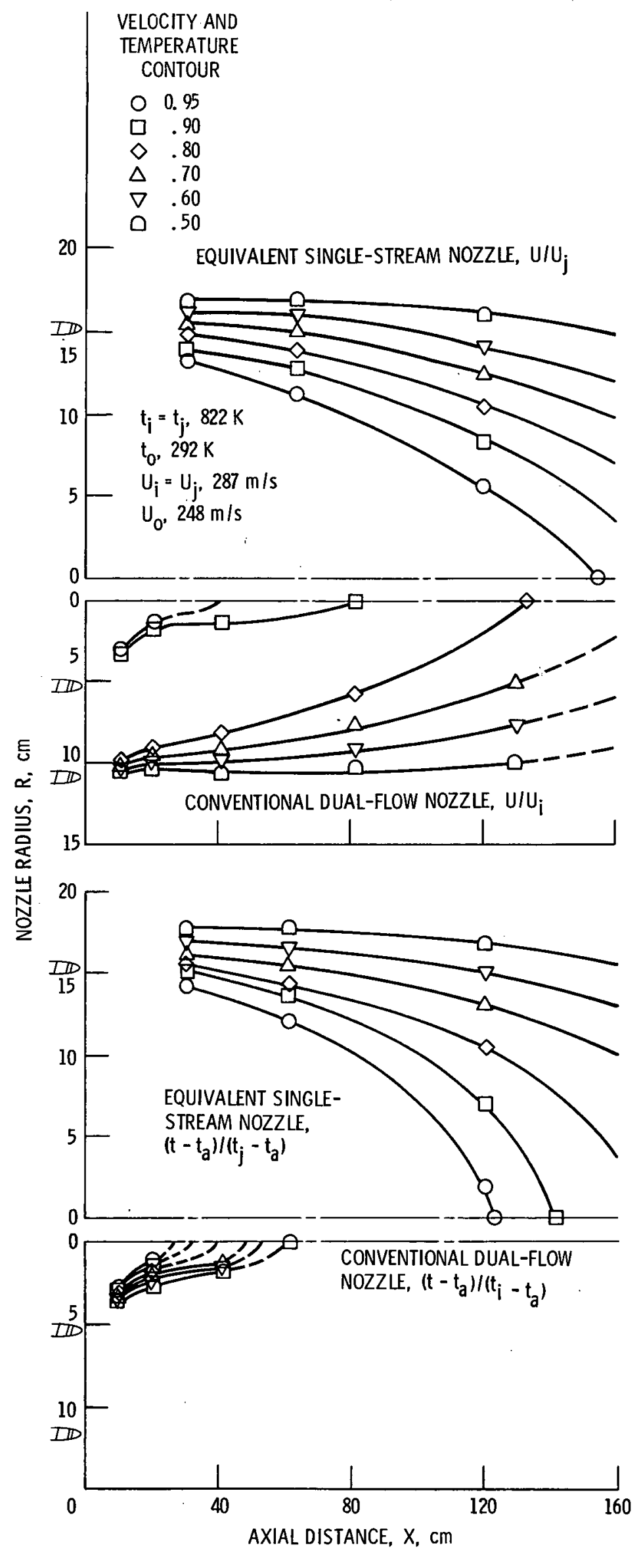

(b) Temperature.

Figure 12. - Velocity and temperature contour map comparison of cold outer-stream conventional dual-flow nozzle plumes with equivalent thrust single-stream nozzle plumes.

AR, 3.2; $U_{0} / U_{i}, 0.86 ; t_{0} / t_{i}, 0.36$. 


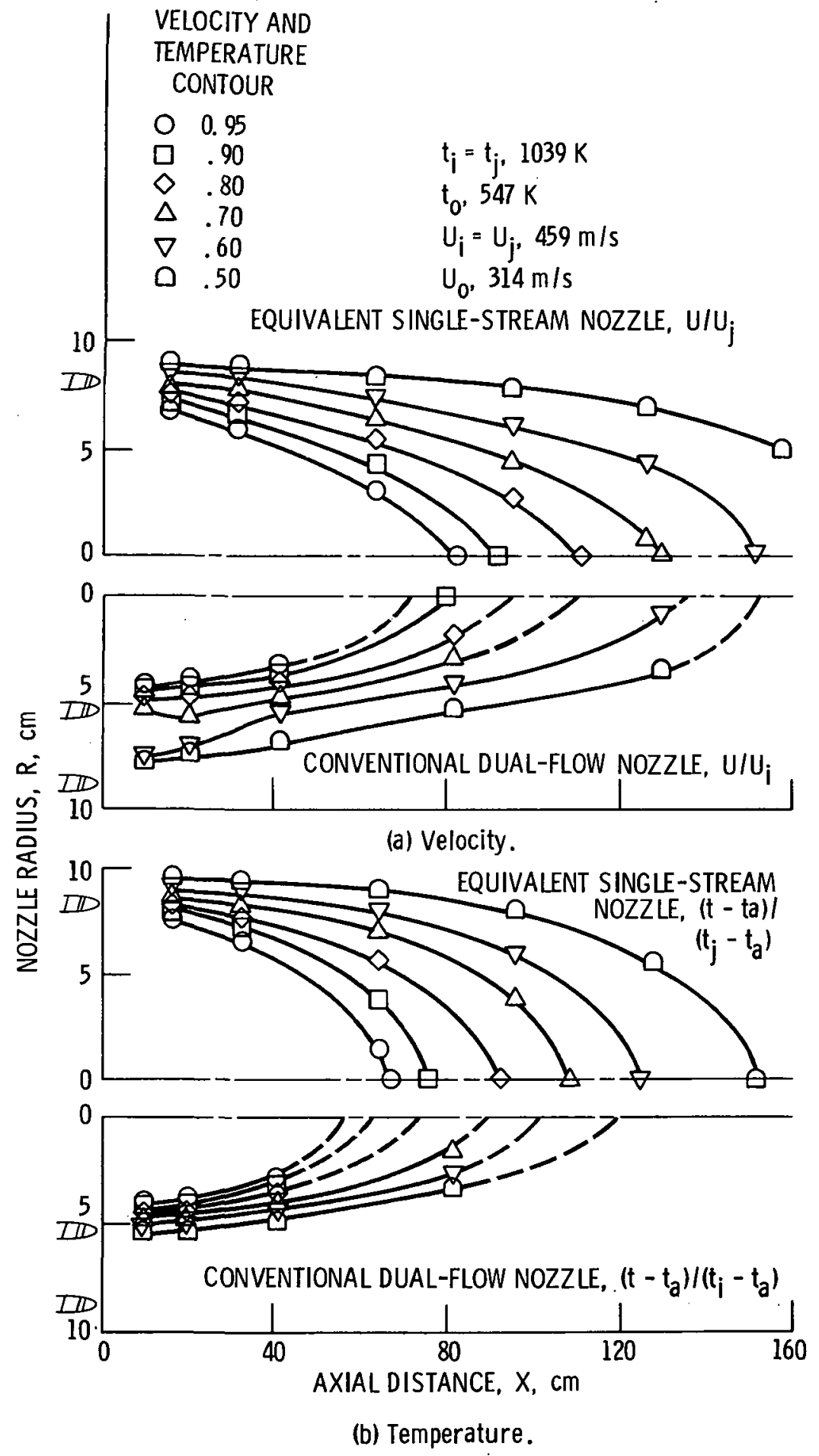

Figure 13. - Velocity and temperature contour map comparison of heated outer-stream conventional dual-flow nozzles plumes with equivalent thrust single-stream nozzle plumes.

AR, $1.9 ; U_{0} / U_{i}, 0.68 ; t_{0} / t_{i}, 0.53$. 


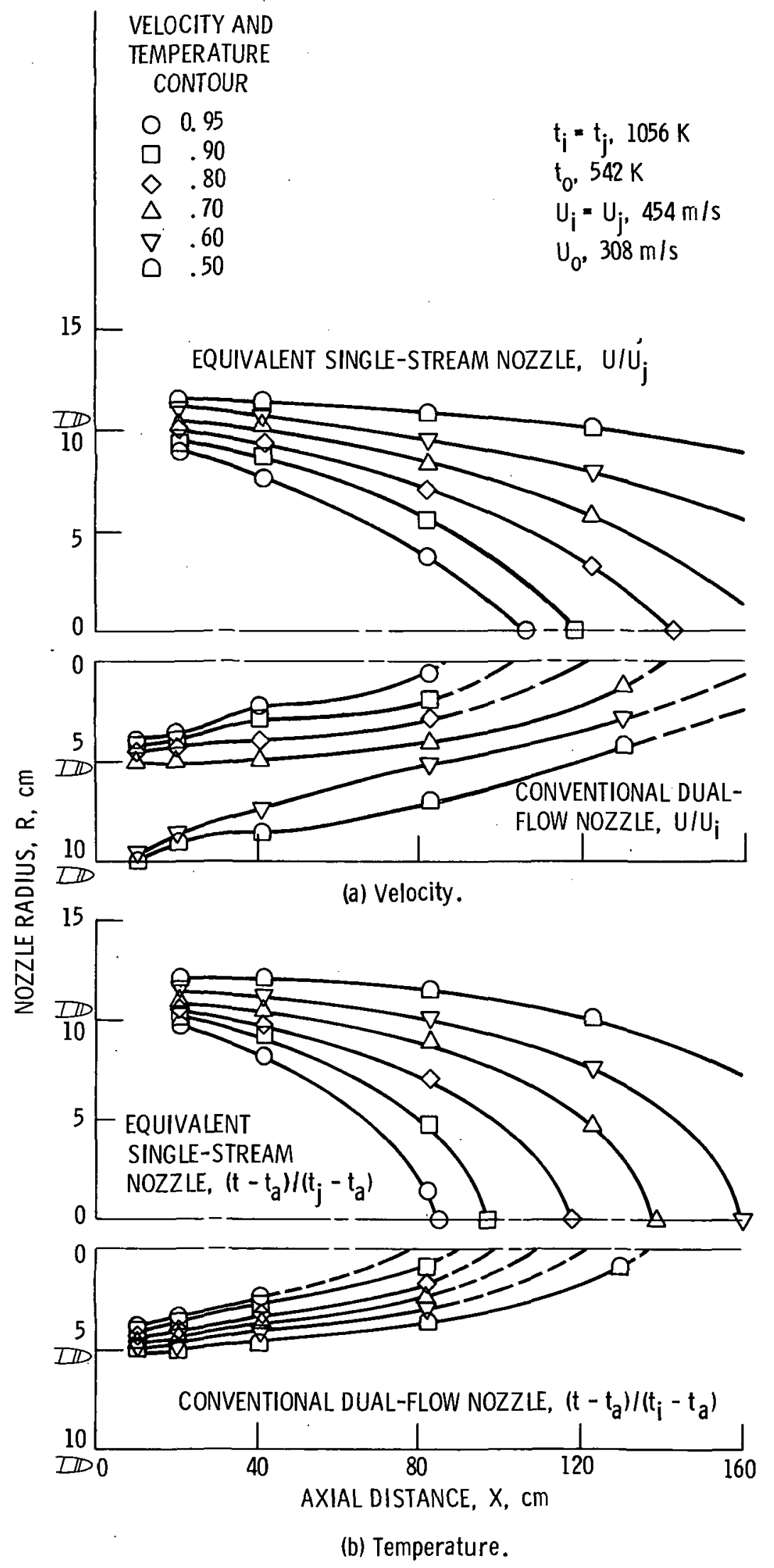

Figure 14. - Velocity and temperature contour map comparison of heated outer-stream conventional dual-flow nozzles plumes with equivalent thrust single-stream nozzle plumes. AR, 3.2; $U_{0} / U_{i}, 0.67 ; t_{0} / t_{j}, 0.51$. 


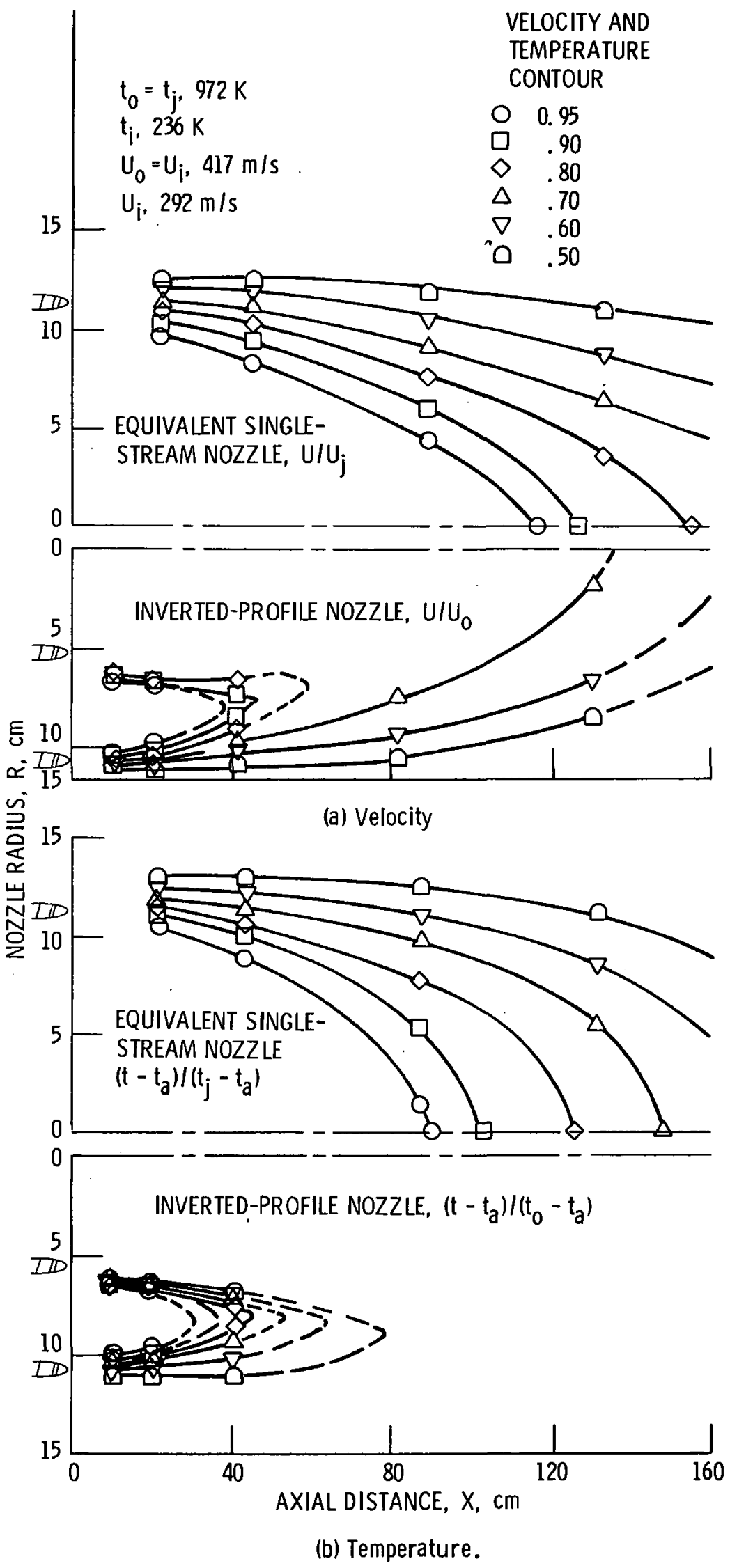

Figure 15. - Velocity and temperature contour map comparison of cold inner-stream inverted profile dual-flow nozzle plumes with equivalent thrust single-stream nozzle plumes. AR, 3.2; $U_{0} / U_{i}, 1.43 ; t_{0} / t_{i}, 4.12$. 


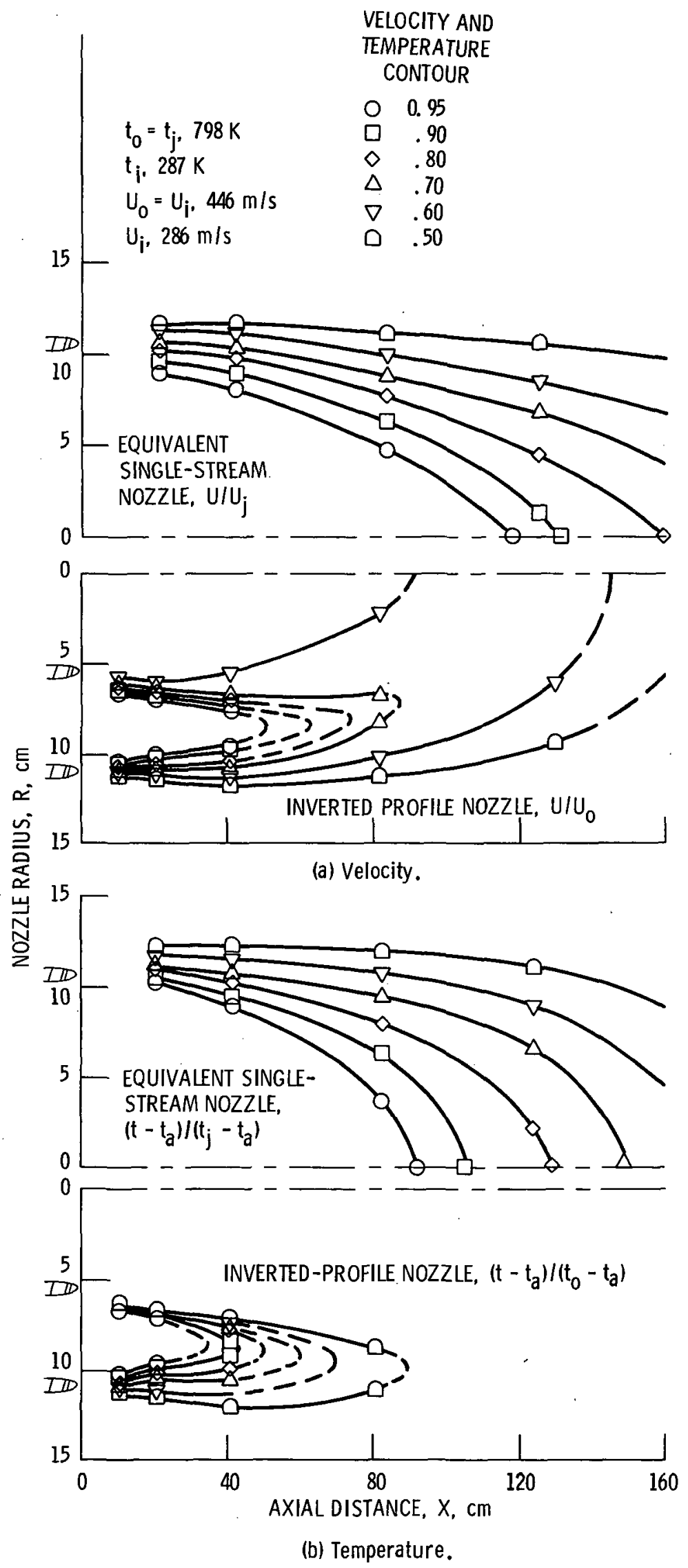

Figure 16. - Velocity and temperature contour map comparison of cold inner-stream inverted profile dual-flow nozzle plumes with equivalent thrust single-stream nozzle plumes. AR, 3.2 ; $\mathrm{U}_{0} / \mathrm{U}_{\mathrm{i}}, 1.55 ; \mathrm{t}_{0} / \mathrm{t}_{\mathrm{i}}, 2.78$. 


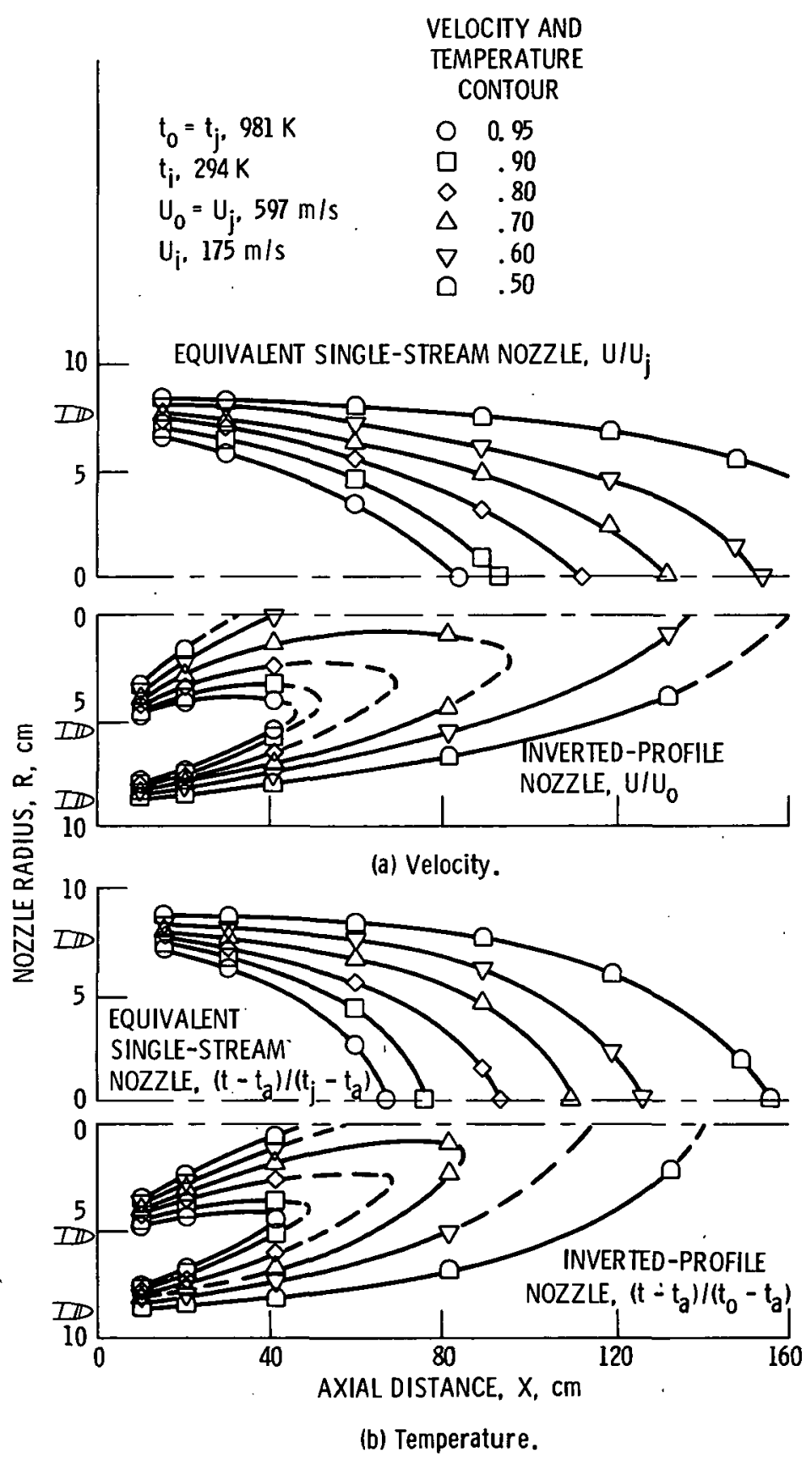

Figure 17. - Velocity and temperature contour map comparison of cold inner-stream inverted-profile dual-flow nozzle plumes with equivalent thrust single-stream nozzle plumes. AR, 1.9; $\mathrm{U}_{0} / \mathrm{U}_{\mathrm{i}}, 3.4 \mathrm{l} ; \mathrm{t}_{\mathrm{o}} / \mathrm{t}_{\mathrm{i}}, 3.34$. 


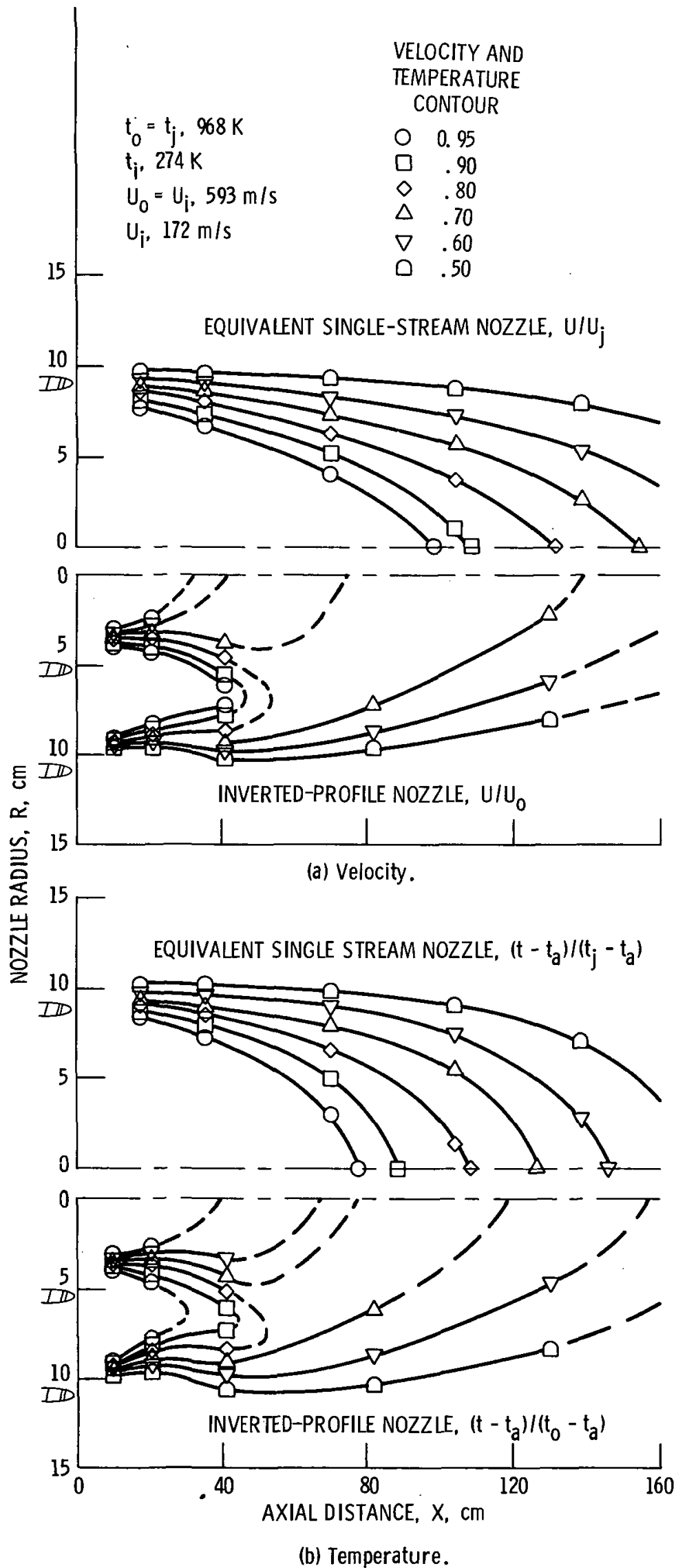

Figure 18. - Velocity and temperature contour map comparison of cold inner-stream inverted-profile dual-flow nozzle plumes with equivalent thrust single-stream nozzle plumes. AR, 3.2; $\mathrm{U}_{0} / \mathrm{U}_{\mathrm{i}}, 3.49 ; \mathrm{t}_{0} / \mathrm{t}_{\mathrm{j}}, 3.53$. 


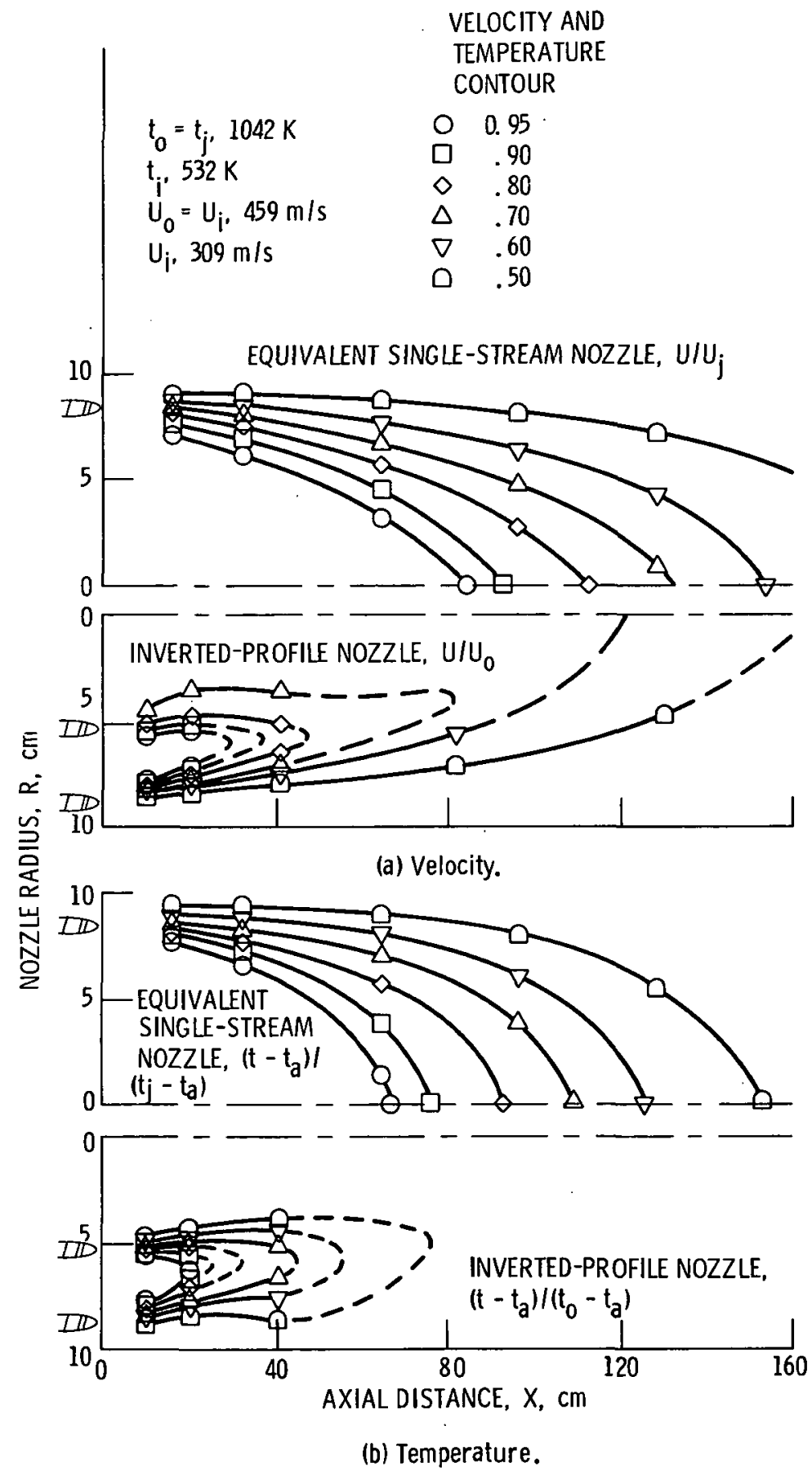

Figure 19. - Velocity and temperature contour map comparison of heated inner-stream inverted-profile dual-flow nozzle plumes with equivalent thrust single-stream nozzle plumes. AR, 1.9; $\mathrm{U}_{0} / \mathrm{U}_{\mathrm{i}}, 1.49 ; \mathrm{t}_{0} / \mathrm{t}_{\mathrm{i}}, 1 . \%$. 


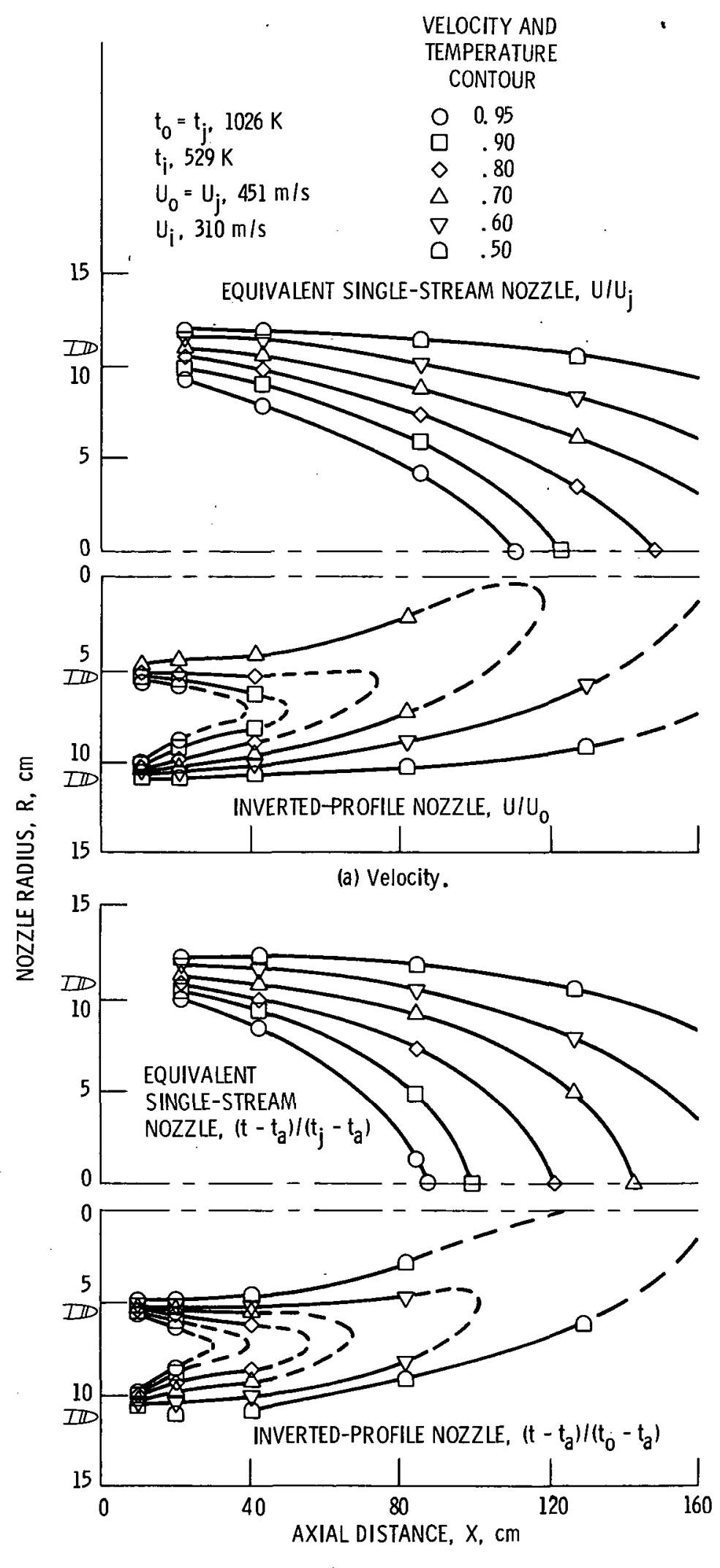

(b) Temperature.

Figure 20. - Velocity and temperature contour map comparison of heated inner-stream inverted-profile dual-flow nozzle plumes with equivalent thrust single-stream nozzle plumes. AR, $3.2 ; U_{0} / U_{i}, 1.47 ; t_{0} / t_{j}, 2.78$. 


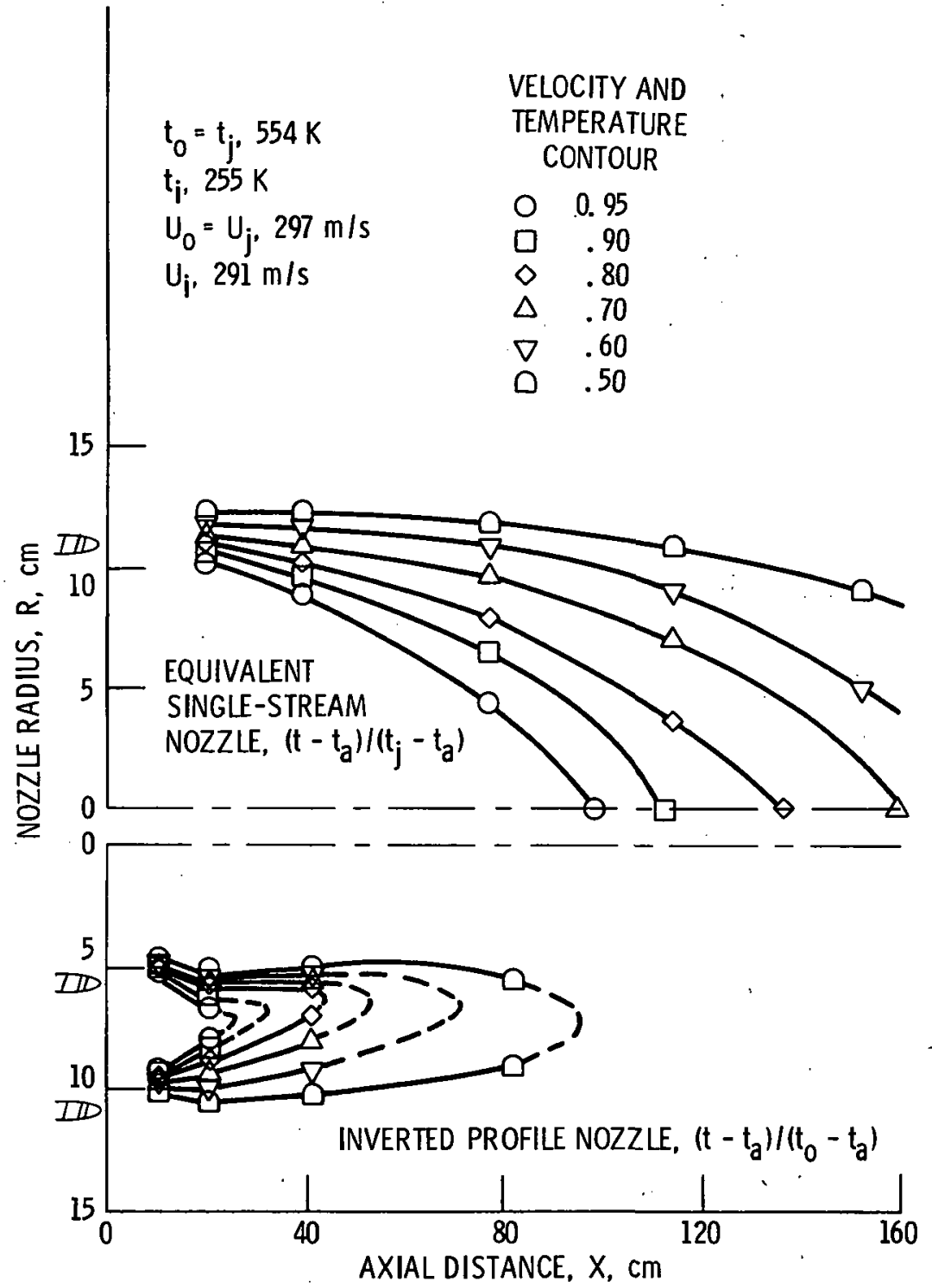

Figure 21. - Temperature contour map comparison of heated innerstream inverted-profile dual-flow nozzle plume with equivalent thrust single-stream nozzle plume. AR, 3.2; $U_{0} / U_{i}, 1.02$; $t_{0} / t_{j}, 2.17$. 


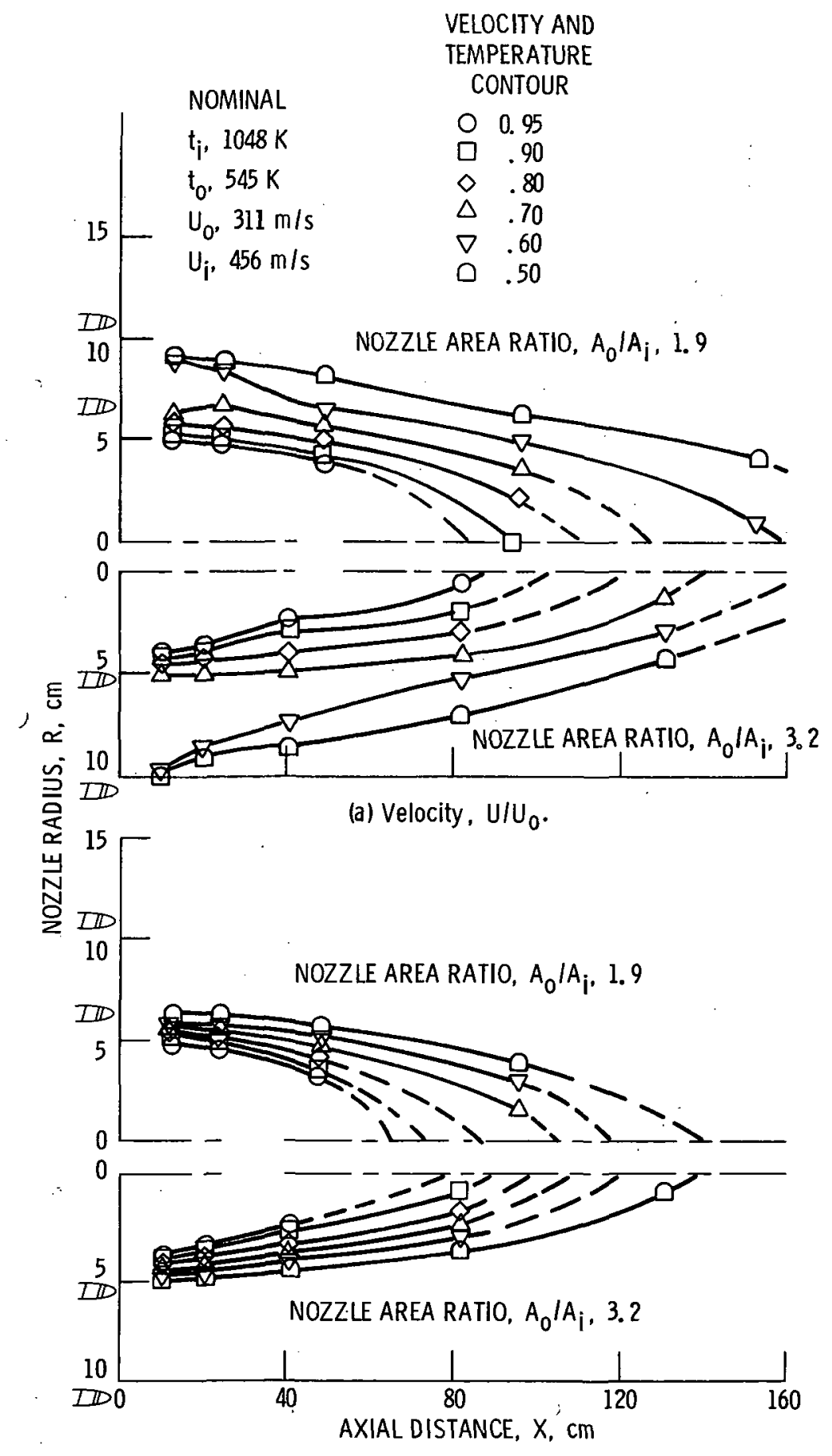

(b) Temperature, $\left(t-t_{a}\right) /\left(t_{i}-t_{a}\right)$.

Figure 22. - Effect of nozzle area ratio on velocity and temperature maps of equivalent thrust heated outer-stream conventional dual-flow nozzle plumes. $U_{0} / U_{j}, 0.68 ; t_{0} / t_{j}, 0.52$. 


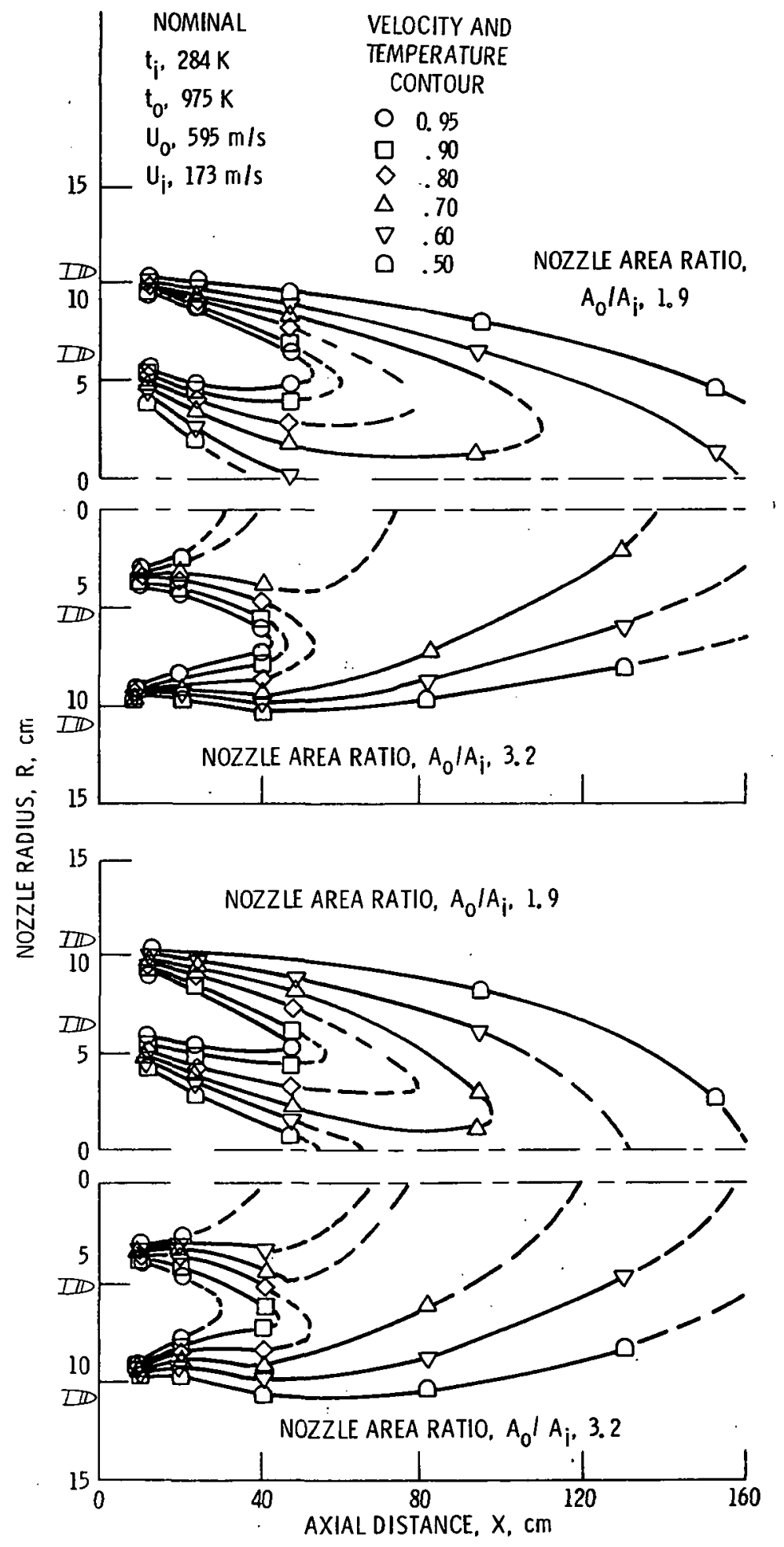

(b) Temperature, $\left(t-t_{a}\right) /\left(t_{0}-t_{a}\right)$

Figure 23. - Effect of nozzle area ratio on velocity and temper ature maps of equivalent thrust cold inner-stream inverted profile dual-flow nozzle plumes. $U_{0} / U_{i}, 3.45: t_{0} / t_{j}, 3.44$. 


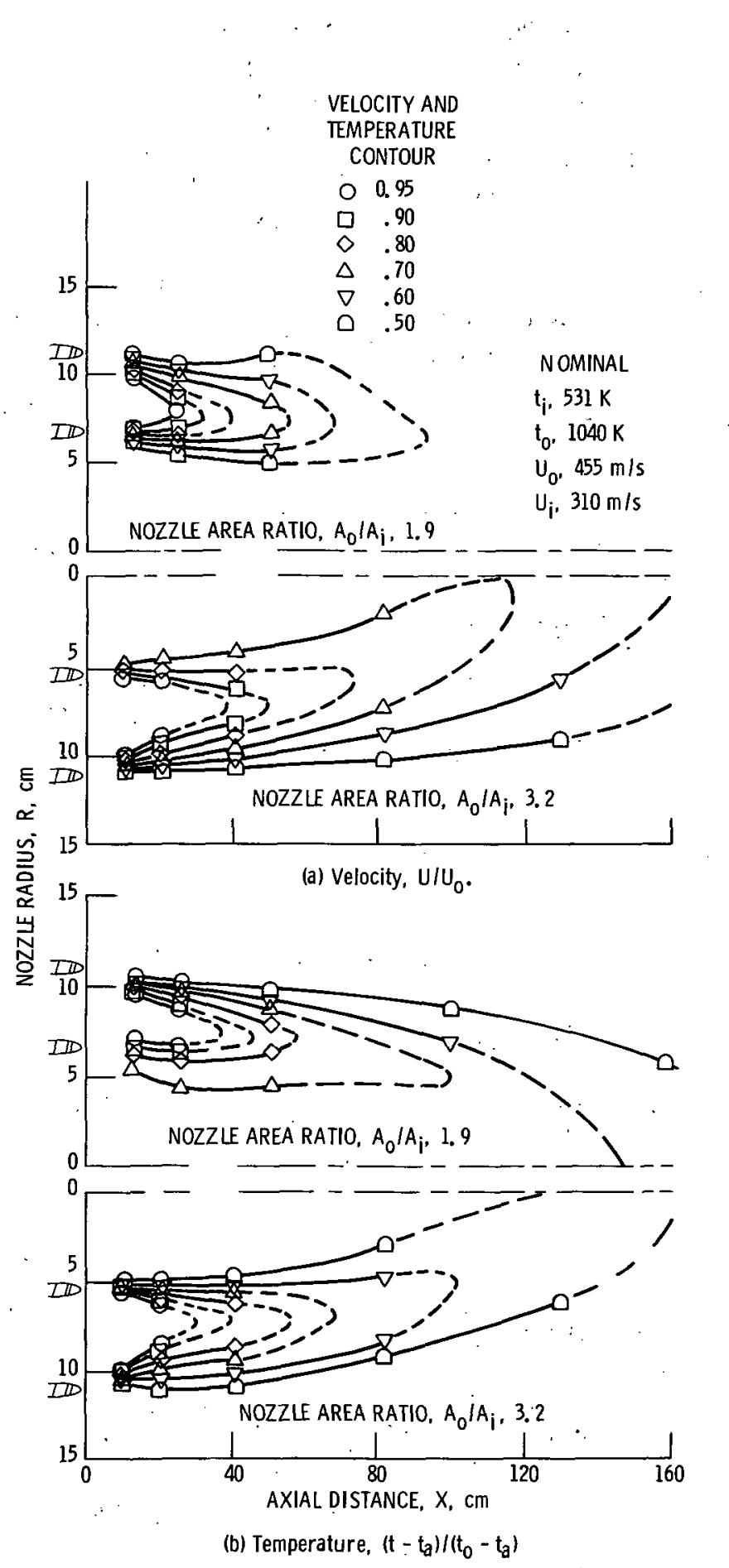

Figure 24. - Effect of nozzle area ratio on velocity and temperature maps of equivalent thrust heated inner-stream inverted profile dual-flow nozzle plumes. $U_{0} / U_{i}, 1.48 ; t_{0} / t_{i}, 1.95$. 


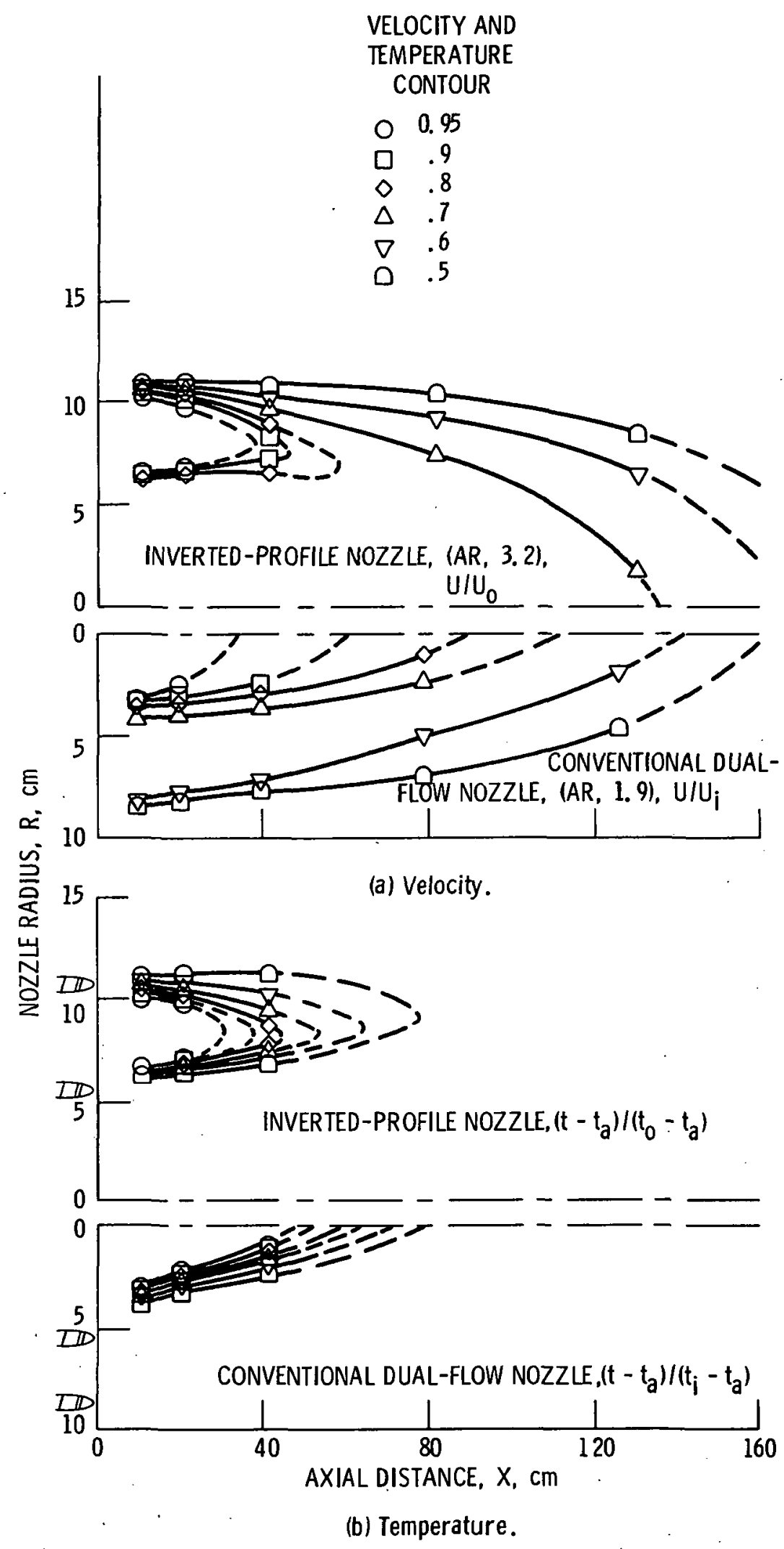

Figure 25. - Velocity and temperature contour map comparisons of inverted-profile, dual-flow nozzle plumes with equivalent thrust conventional dual-flow nozzle plumes. Cold secondary flow; $\left(U_{0} / U_{i}\right)_{c}, 0.68 ;\left(U_{0} / U_{i}\right)_{i p}, 1.43 ;\left(t_{0} / t_{i}\right)_{c}, 0.24 ;\left(t_{0} / t_{i}\right)_{i p}$, 


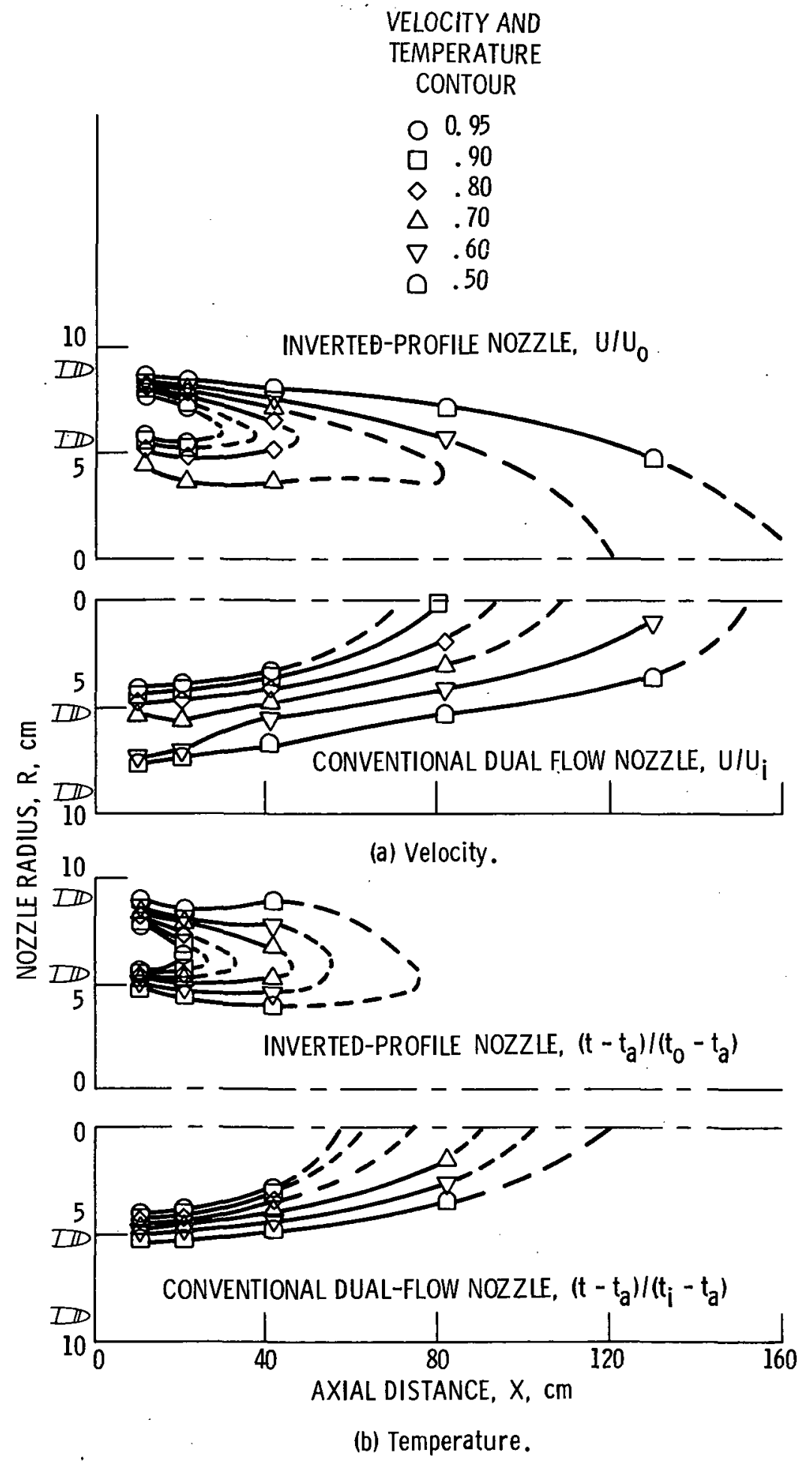

Figure 26. - Velocity and temperature contour map comparisons of inverted profile dual-fl ow nozzle plumes with equivalent thrust conventional dual-flow nozzle plumes. Hot secondary $\therefore$ flow; AR, 1. 9; $\left(U_{0} / U_{i}\right)_{c}, 0.68 ;\left(U_{0} / U_{i}\right)_{i p}, 1.49 ;\left(t_{0} / t_{i}\right)_{c}$, $0.53 ;\left(t_{0} / t_{i j}\right)_{i p}, 1.96$. 


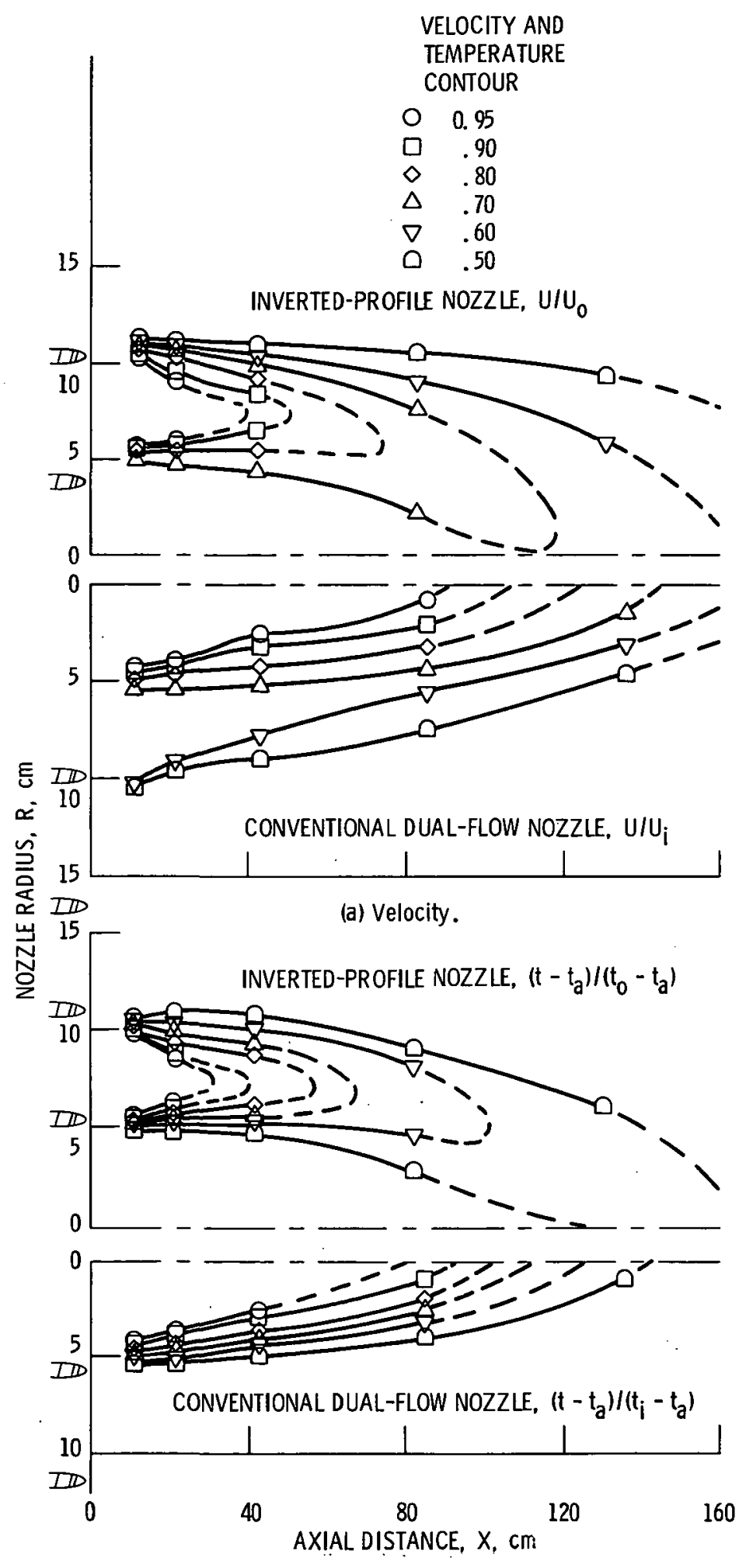

(b) Temperature.

Figure 27. - Velocity and temperature contour map comparisons of inverted profile dual-flow nozzle plumes with equivalent thrust conventional dual-flow nozzle plumes. Hot secondary flow; AR, 3.2; $\left(U_{0} / U_{i}\right)_{c}, 0.67 ;\left(U_{0} / U_{i}\right)_{i p}, 1.47 ;\left(t_{0} / t_{i}\right)_{c}, 0.51$; $\left(t_{0} / t_{i}\right)_{i p} \cdot 1.94$. 


\begin{tabular}{|c|c|c|}
\hline $\begin{array}{l}\text { 1. Report No. NASA TM-87323 } \\
\text { AIAA-86-1809 }\end{array}$ & 2. Government Accession No. & 3. Recipient's Catalog No. \\
\hline \multicolumn{2}{|l|}{ 4. Title and Subtitle } & 5. Report Oate \\
\hline \multicolumn{2}{|c|}{$\begin{array}{l}\text { Plume Characteristics of Single-Stream and Dual- } \\
\text { Flow Conventional and Inverted-Proftle Nozzles } \\
\text { at Equal Thrust }\end{array}$} & $\begin{array}{l}\text { 6. Performing Organization Code } \\
505-62-91\end{array}$ \\
\hline \multicolumn{2}{|c|}{ Uwe $H$. von Glahn and Jack H. Goodykoontz } & $\begin{array}{l}\text { 8. Performing Organization Report No. } \\
\text { E-3060 }\end{array}$ \\
\hline \multicolumn{2}{|c|}{$\rightarrow 03,15 \%$} & 10. Work Unit No. \\
\hline \multirow{2}{*}{\multicolumn{2}{|c|}{$\begin{array}{l}\text { 9. Performing Organization Name and Address } \\
\text { National Aeronautics and Space Administration } \\
\text { Lewis Research Center } \\
\text { Cleveland, Ohio } 44135\end{array}$}} & 11. Contract or Grant No. \\
\hline & & 13. Type of Report and Period Covered \\
\hline \multicolumn{2}{|l|}{ 12. Sponsoring Agency Name and Address } & Technical Memorandum \\
\hline \multicolumn{2}{|c|}{$\begin{array}{l}\text { National Aeronautics and Space Administration } \\
\text { Washington, D.C. } 20546\end{array}$} & 14. Sponsoring Agency Code \\
\hline \multicolumn{3}{|c|}{ 15. Supplementary Notes } \\
\hline \multicolumn{3}{|c|}{$\begin{array}{l}\text { Prepared for the Fourth Applifed Aerodynamics Conference sponsored by the American } \\
\text { Institute of Aeronautics and Astronautics, San Diego, California, June 9-11, } 1986 .\end{array}$} \\
\hline \multicolumn{3}{|l|}{ 16. Abstract } \\
\hline \multicolumn{3}{|c|}{$\begin{array}{l}\text { The plume velocity and temperature decay rates of single-stream, conventional } \\
\text { dual-flow and inverted-profile dual-flow nozzles are compared at equal values of } \\
\text { ideal thrust over a wide range of flow conditions. The comparisons are made in } \\
\text { terms of constant velocity and temperature contour maps. The results show that } \\
\text { both dual-flow nozzle types have much greater plume velocity and temperature decay } \\
\text { rates than those of equivalent thrust single-stream nozzles when the respective } \\
\text { secondary flows were at ambient temperature. With hot secondary flows, the } \\
\text { inverted-profile dual-flow plumes decayed significantly faster than those of } \\
\text { single-stream nozzles; however, the decay rates for the conventional dual-flow } \\
\text { streams were about the same as those for the single-stream nozzles. Consequently, } \\
\text { with hot secondary flows, the inverted-profile dual-flow plumes decayed much } \\
\text { faster than the conventional dual-flow plumes at equal thrust. }\end{array}$} \\
\hline \multicolumn{3}{|l|}{ 17. Key Words (Suggested by Author(s)) } \\
\hline Jet plume & & $\begin{array}{l}\text { Unclassified - unlimited } \\
\text { STAR Category } 02\end{array}$ \\
\hline $\begin{array}{l}\text { 19. Security Classif. (of this report) } \\
\text { Unc lass if I ied }\end{array}$ & $\begin{array}{l}\text { Security Classif. (of this page) } \\
\text { Unc lass iffed }\end{array}$ & $\begin{array}{c}\text { 21. No. of pages } \\
39\end{array}$ \\
\hline
\end{tabular}

*For sale by the National Technical Information Service, Springfield, Virginia 22161 
National Aeronautics and

Space Administration

Lewis Research Center

Cleveland. Ohio 44135

Official Business

Penalty for Private Use $\mathbf{5 3 0 0}$
SECOND CLASS MAIL

ADDRESS CORRECTION REQUESTED

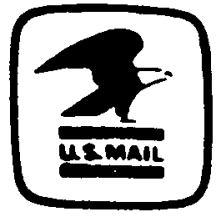

Postage and Fees Paid National Aeronautics and Space Administration NASA-451 